\title{
Chapter
}

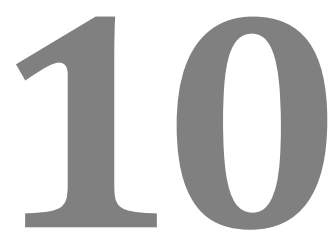

\section{INTRACELLULAR DELIVERY AND SENSING BASED ON POLYELECTROLYTE MULTILAYER CAPSULES}

Moritz Nazarenus*, Pilar Rivera Gil, and Wolfgang J. Parak

Fachbereich Physik, Philipps Universität Marburg, Germany

${ }^{*}$ Corresponding author: moritz.nazarenus@googlemail.com

** This book chapter is based on the PhD thesis „Polyelectrolyte Multilayer Capsules for Medical Applications", by Dr. Moritz Nazarenus, Philipps-Universität Marburg, Marburg, Germany (2014). 


\section{Contents}

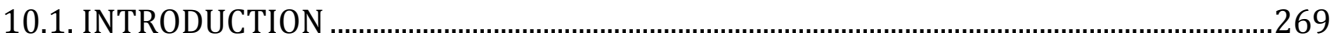

10.1.1. Polyelectrolyte multilayer capsules .......................................................................269

10.2 APPLICATION I: DELIVERY

10.2.1. Responsive polymers as internal triggers to mediate cargo release................2272

10.2.1.1. Biodegradable capsules as non-viral vectors........................................22

10.2.1.2. Delivery of DNA ........................................................................................273

10.2.1.3. Delivery of siRNA to block the expression of green fluorescence protein (GFP).......................................................................275

10.2.1.4. Cytotoxicity of PEI polyplexes and encapsulated PEI............................278

10.2.2. Light acting on Plasmonic nanoparticles as external trigger to

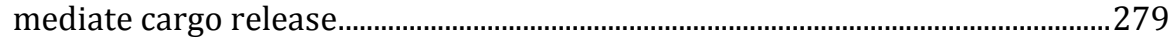

10.2.2.1. Delivery of mRNA with light-responsive capsules.................................28

10.2.2.2. Protein release from light-responsive capsules......................................283

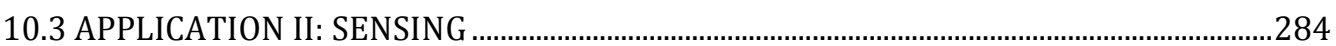

10.3.1. pH sensing with fluorescent dyes ............................................................................284

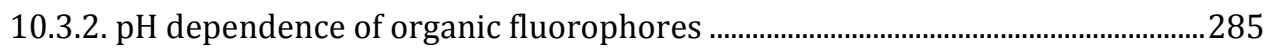

10.3.3. Intracellular pH sensing with capsules.............................................................286

10.4 THERANOSTICS AS BIOMEDICAL APPROACH FOR POLYELECTROLYTE

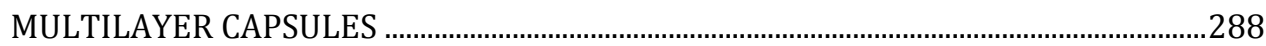

10.4.1. Capsules for sensing and enzyme delivery in lysosomal storage

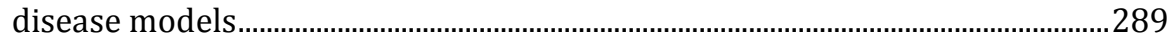

10.4.1.1. Lysosomal storage disorders......................................................................28

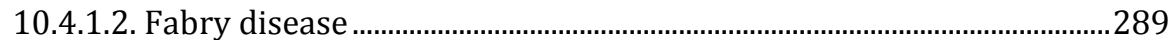

10.4.1.2.1. Determination of GLA content of capsules by Western Blot290

10.4.1.2.2. Intracellular effect of GLA and GLA capsules.........................290

10.4.1.3. Krabbe disease ........................................................................................291

10.4.1.3.1. pH sensing in M03.13 oligodentrocytes...................................292

10.4.1.3.2. Delivery of galactocerebrosidase to MO3.13

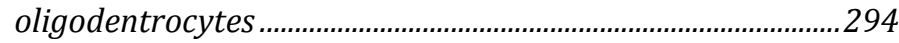

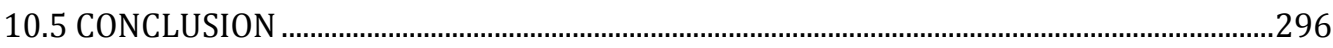

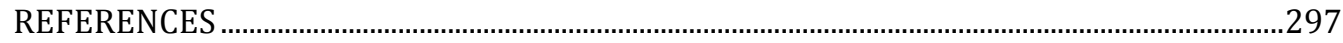




\subsection{INTRODUCTION}

\subsubsection{Polyelectrolyte multilayer capsules}

Polyelectrolyte multilayer capsules were first introduced in 1998 by the group of Helmuth Möhwald and coworkers, and since then have gained increasing interest over the years, especially in biomedical fields [1,2]. These capsules are typically fabricated using template particles, onto which polymers of alternating charge are deposited using layer-by-layer (LbL) assembly [2]. After dissolution of the template, stable hollow capsules remain. The size and the shape of the capsules are thereby dependent on the choice of templates, whereas the physico-chemical properties are determined by the polymers. Yashchenok et al. produced anisotropic, i.e. non-spherical calcium carbonate cores, and showed that the resulting capsules kept the form of the templates after their removal [3]. Different materials, such as polystyrene, silica or calcium carbonate have been used to fabricate capsule cores [4], but even red blood cells or Escherichia coli can be used $[5,6]$. With the right choice of template the capsules can be tuned in size from $30 \mathrm{~nm}$ up to several microns, opening the way for customization of the capsules according to the problem of interest [4]. Very small capsules of tens of nanometers can be produced with silica templates, whereas capsules assembled on calcium carbonate cores typically reach sizes of 2-10 microns. Capsules can be produced with a great variety of different polymers. The most widespread and best understood pair of polymers is the system of poly(styrene sulfonate) (PSS) and poly(allyamine hydrochloride) (PAH). However, there are many other polymers in use and it is also possible to produce biodegradable capsules made of polymers that can be digested/metabolized inside living cells, for example by proteases present in the lysosome [7,8]. There are two ways to load the capsules, the coprecipitation method, where the cargo is entrapped in the template and remains inside the capsules after removal of the template material, and the postloading method, where the permeability of the capsules can be controlled externally by variation of $\mathrm{pH}$, salt concentration or temperature [9], and the cargo can be loaded into the empty capsules after the synthesis [10]. During the removal of the template core the capsules become much more porous due the osmotic pressure that arises by dissolving the core. This is the main reason why cargo is lost during the fabrication of capsules using the co-precipitation method. There are also other ways of synthesizing capsules, apart from the LbL method and the reader is referred to recent reviews on capsules as biological carriers for further information $[4,11,12]$. The capsule wall represents a semipermeable membrane, as small molecules can diffuse almost freely through the pores [13], whereas large molecules, for example dextran molecules or proteins, cannot pass the capsule walls. The molecular weight cut-off (MWCO) for PSS/PAH is around 200 Da [14]. The MWCO depends on the polymers, and 
Miller and Bruening showed that, for example, the combination of hyaluronic acid (HA) and chitosan had a MWCO of $\approx 17,000$ Da $[14,15]$. Due to the semipermeability of the capsule wall a Donnan equilibrium occurs [16], which means that the concentration of ions and molecules inside of the capsules is different of the concentrations outside, also in case of molecules or ions, for which the membrane is permeable. Sukhorukov et al. showed, for example, in a theoretical model that the $\mathrm{pH}$ inside capsules is different from that in the solution [17]. The permeability of capsules reduces as the pores of the capsules close over time. This effect can also be achieved by enhancing the temperature to anneal the pores $[18,19]$. The permeability of the capsules walls is furthermore influenced by the hydration of the polymer multilayers and the charge densities of the polymers. With higher charge densities the permeability of the capsule walls decreases and the hydration is reduced [15]. Hydration of the polyelectrolytes has not only an effect on permeability but also on the thickness of the layers as well as the interaction of the polymers, and the elasticity of the capsule shells [20]. In case of PSS/PAH, the amount of water associated with PSS is roughly double as much as the amount associated with PAH [21]. It has to be noted that the water content of planar polyelectrolyte multilayer films is smaller than that of capsules. This means that the planar films are packed more densely than the capsule walls. The difference is about $45-55 \%$ of water [20]. Furthermore, the water content of the multilayers is dependent on the outermost layer. Wong et al. showed that water is pressed out of the multilayer when PAH is adsorbed as top layer and that more water is absorbed by the shell when PSS is the top layer [22]. The outer layers are thereby more sensitive to the environmental humidity than the inner layers. This means that with increasing numbers of layers the inner layers are more and more unaffected by hydration [23]. Concerning applications of capsules in biomedical fields, they can generally be divided into delivery and sensing applications [24,25]. A large size of the capsules can be of advantage in cell culture models, as large capsules are easily traceable with optical techniques. In contrast, small capsules in the size of nanometers are of interest for in vivo applications, where large capsules cannot be used as they may block capillaries. The cellular uptake is a statistical process that in vitro occurs in almost all mammalian cells, both immortal cell lines and primary cells [26-28]. It is triggered by phagocytosis and lipid-rafts-mediated macropinocytosis and the final location of the capsules is in the heterophagolysosomes of the cells [27]. One should note that the uptake is dependent on the shape of the capsules. Spherical capsules are internalized faster and in higher quantities compared to anisotropic capsules, yet the final location is not affected [29]. After cell division, the capsules are passed to the daughter cells [8]. The distribution, however, is asymmetric, i.e. they are not passed on in a fifty-fifty manner [30,31]. Capsules can be filled with various cargos for delivery, among them drugs, genetic material like desoxyribonucleic acid (DNA) or ribonucleic acid (RNA), or proteins [12,32-37]. The experimental challenges lie in the difficulties to encapsulate certain cargos in a sufficient 
way, but also in problems to release the cargo at the desired target site. Concerning release, one major challenge is to free the capsule content from the organelle, i.e. the lysosome where the capsules are located after incorporation into cells, so that the cargo becomes available to reach targets outside this vesicle. For sensing applications the capsules can be filled with a sensor that does not necessarily need to be released. Often, this is a dye sensitive to a specific ion or other analyte, respectively [38-41]. These dyes are widespread as they are easy to handle and there is a large variety of dyes for many different analytes commercially available. Moreover, the biocompatibility of organic fluorophores usually is not an issue as they typically show very low or no toxicity [42]. Dyes need to fulfill certain requirements to be suitable for the use in sensor capsules for intracellular sensing. Fluorophores with the absorption maximum in the UV to blue range, for example, may be problematic as autofluorescene can occur in the cells. Moreover, light of short wavelength has high energies and may thus be harmful to the cells. To entrap the dye molecules inside the capsule cavity, they need to contain functional groups, with which they can be conjugated to dextrans or other large molecules so they cannot diffuse through the capsule walls. These conjugations must be possible without the dye molecules losing their fluorescent properties and analyte sensitivity. Depending on the application, the photostability of the dye may be an important parameter. Many fluorophores bleach fast in biological media, which can be problematic, for instance in long-term experiments. The spectra of fluorescent dyes often are quite broad and therefore multiplexed measurement with dyes, i.e. the sensing of two or more analytes simultaneously, is limited due to spectral overlap of the dyes [42]. Additionally one has to keep in mind when working with dyes, that crosstalk can occur from different ions or $\mathrm{pH}[39,43]$. As will be highlighted further in the section on sensing, many organic fluorophores are sensitive to more than one ion and the fluorescence may also be dependent on the local pH. Besides dyes, also more complex sensor systems have been described, such as enzymes that convert a metabolite and a component that gives a signal quantifying the conversion [4446]. 


\subsection{APPLICATION I: DELIVERY}

Delivery and release of carried compounds from the carrier (capsules) is still a challenge that affects the performance of the compound and of the carrier itself. Release of the cargo must be ensured not only from the carrier but also from the vesicle in which the carrier is entrapped. There are different strategies to ensure this. With help of triggers (internal or external) opening of the carrier can be performed. Internal triggers include responsive polymers that are sensitive to their environment, whereas external triggers can be electromagnetic waves, magnetic fields, or heat, for example. Release from the vesicle can be achieved by changing the osmotic pressure of the organelle. All this strategies will be described in the following.

\subsubsection{Responsive polymers as internal triggers to mediate cargo release}

In this case, polymers which are sensitive to degradation/metabolization by lysosomal enzymes are used as constituents of the capsule wall. When capsules of this nature enter the lysosomes, wall degradation occurs and cargo release follows $[8,47,48]$. An example of success of this strategy has been described by demonstrating the release of genetic material (DNA and silencing RNA (siRNA)) [36] and will be described in more detail in the following. Indirectly, the delivery of cargo to the cytosol of the cell (out of the organelle) was demonstrated in this study by measuring the activity of siRNA after reaching its target messenger RNA (mRNA) located in the cytosol. Cytosolic release was herby not performed by the polymers of the capsules but by encapsulated polymers capable of disrupting the lysosomes of the cells. The lysosomal escape in this case was ascribed to the so-called proton sponge effect [49-51], although this effect is still under debate. The proton sponge effect is stated to take place when polycations with buffering capacity, such as poly(ethylenimine) (PEI), which at slightly acidic $\mathrm{pH}$ contains many deprotonated amine groups, buffer the $\mathrm{pH}$ in the lysosomes. The lysosomal $\mathrm{pH}$ hence does not decrease when proton pumps transfer protons from the outside into the lysosomes and thus influx of further protons takes place [52]. To ensure the charge and ion activity equilibrium across the lysosomal membrane, also chloride and water enter the lysosomes. This leads to swelling of the lysosomes. When the pressure increase is high enough, the vesicles finally burst releasing their content to the cytosol [53].

\subsubsection{Biodegradable capsules as non-viral vectors}

Despite the established methods, there is need for other or improved means of delivery of genetic material to cells. Viral vectors usually show a high transfection rate and are therefore the preferred vectors. They, however, raise concerns because of mutagenesis, i.e. the possibility that the viral vectors trigger mutations of the genome, and immunogenicity, i.e. the possibility that 
viral vectors induce an unwanted immune response [54-56]. Non-viral vectors such as lipoplexes and polyplexes, in contrast, show only small transfection rates. Microinjection does not allow for high numbers of transfected cells, as the transfection is very time-consuming and in general not well automatable. Furthermore, it generally does not allow for in vivo transfection, which is also true for electroporation. Thus, there is need for new carriers for transfection both in vitro and in vivo. A bio-compatible carrier is desired, which protects the genetic material against degradation, before it reaches its target, facilitates cell internalization, and enables controlled release of the genetic material [57]. Biocompatible capsules have been synthesized by many groups and subsequent release into the cytosol has been achieved for different cargos, such as proteins, DNA, or RNA $[8,26,33,34,58,59]$.

\subsubsection{Delivery of DNA}

Ganas et al. performed a comparative study where the delivered amount of DNA was quantified for different delivery systems [36]. Cells were incubated with plain DNA, PEI/DNA polyplexes, PEI/DNA polyplexes encapsulated in biodegradable capsules, and PEI/DNA polyplexes encapsulated in nondegradable capsules. Standard transfection protocols with polyplexes were performed in serum-free growth medium [60]. Here, a comparison for media with and without serum was performed. The amount of DNA for each of the experiments was equal so that a comparison based on the administered amount of DNA was possible. In Figure 1, images of HeLa cells at different points in time and for the different ways of delivery are shown. The images show cells incubated without serum. The DNA was labeled with the fluorophore Cy5 and is colored in violet and PEI was labeled with fluorescein isothiocyanate (FITC) and is colored in green in the images. The result of the overlay of violet and green is white. In the images, one can see that cells with plain DNA and PEI/DNA polyplexes show no fluorescence signal at any point in time. With both capsule types, the cells show fluorescence signal, but only cells incubated with biodegradable capsules show fluorescence in the cytosol, whereas in non-degradable capsules the signal is confined to the area of the capsules. The PEI, however, is distributed in the cytosol also in case of nondegradable capsules. Note that the amount of PEI/DNA polyplexes is very small compared to what is stated in standard protocols. This was due to the small amounts needed for the delivery by capsules and the fact that the comparison was based on the amount of DNA added to the cells. Furthermore, the cells begin to become spherical at later times as the serum-free medium stresses them. 


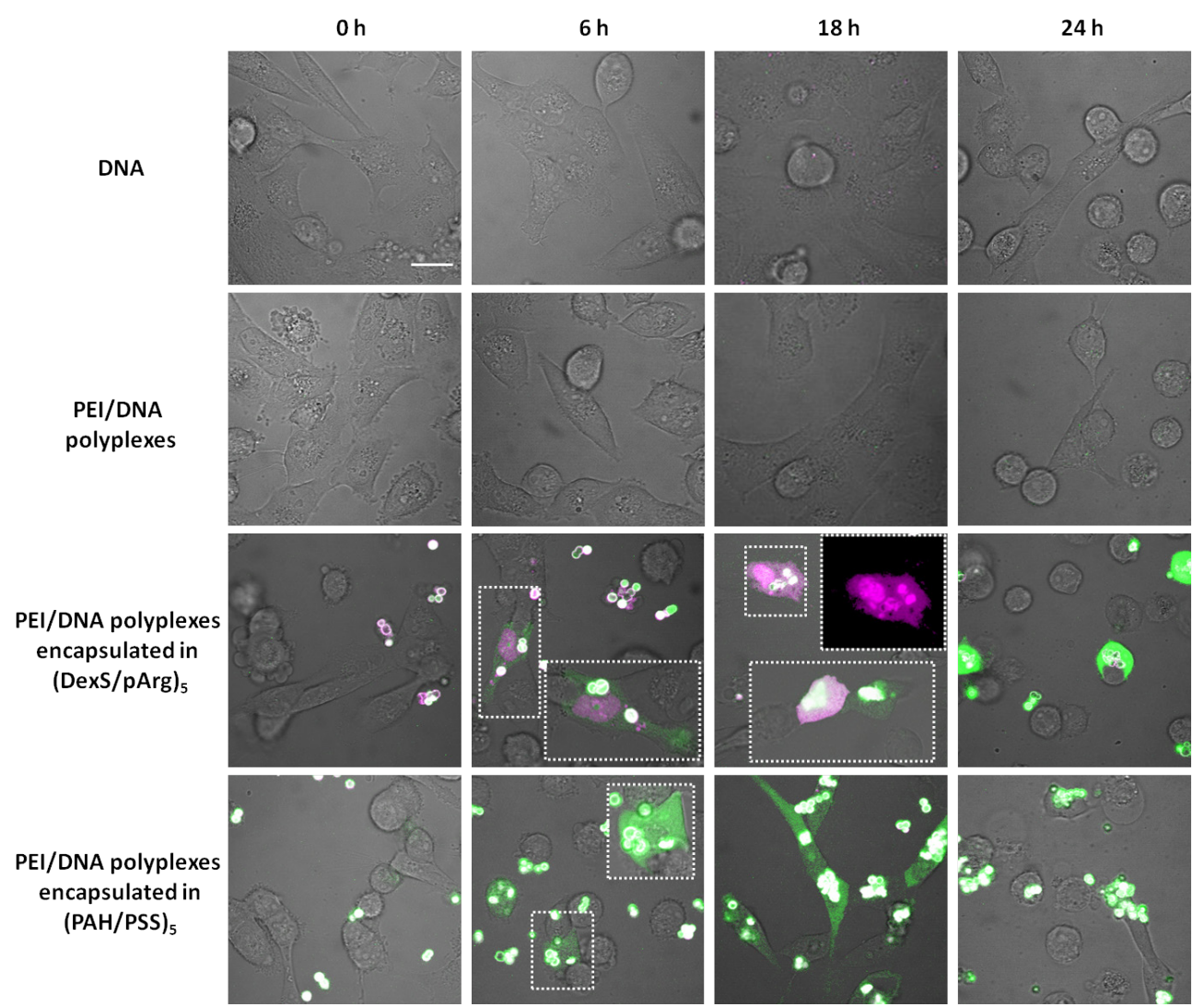

Figure 1. MDA-MB-231 cells were incubated with free DNA, DNA/PEI polyplexes, biodegradable (DexS/pArg) $)_{5}$ capsules with walls made out of dextran sulfate (DexS)

and poly(L-arginine) (pArg) with embedded PEI/DNA, and non-degradable (PSS/PAH) $)_{5}$ capsules with walls made out of poly(sodium 4-styrenesulfonate) (PSS) and PAH with embedded PEI/DNA. After different incubation times, $t$, as indicated in the top panel, cells were imaged. The transmission channel shows the cells, and the green and violet channels show the emission of the FITC labels and Cy5 labels of PEI and DNA, respectively. Images from serum-free experiments are shown. The scale bar corresponds to $20 \mu \mathrm{m}$. The figure has been taken from reference [36]. Reprint with permission from Elsevier.

The delivery efficacy was quantified by quantitative image analysis. The area of each cell was determined from the transmission channel and the mean fluorescence intensity in that area was measured. Fluorescence from the area of the capsules was not included. The mean fluorescence of the cells was averaged and plotted as column diagrams in Figure 2. The left graph corresponds to serum-free incubation and the right graph to cells in serum-supplemented medium. The amount of DNA delivered was highest for biodegradable capsules and already took place within less than 24 hours of incubation. DNA transport was not observable for free DNA or PEI/DNA 
polyplexes in serum-free medium. However, non-degradable capsules could deliver a small but observable amount in serum-free medium. In serum-supplemented medium, free DNA and PEI/DNA polyplexes show a small effect. Nevertheless, here, as well as in serum-free medium, the biodegradable capsules had a much higher efficacy. Moreover, the amount of delivered DNA with biodegradable capsules was found to be clearly higher in serumsupplemented medium than in serum-free medium. Cells deprived of serum suffer from stress, which in turn influences the metabolism. Therefore, transfection in serum-supplemented medium is clearly preferred. Ganas et al. showed that transfection with biodegradable capsules offers a possibility to do that and the capsules provide protection for the DNA in the extracellular medium [36].
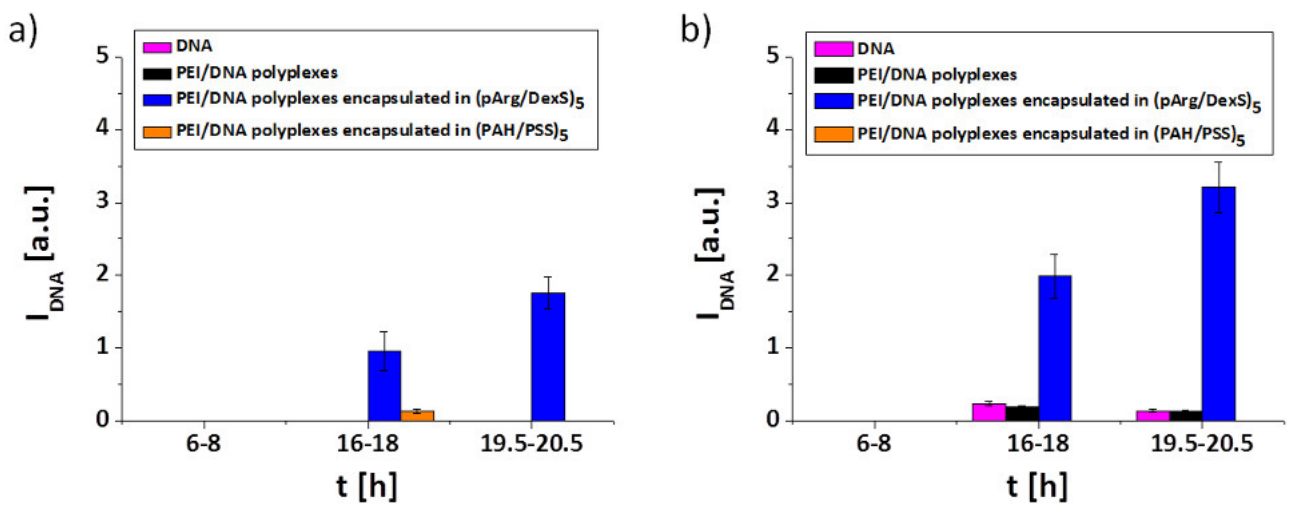

Figure 2. From the microscopy data as presented in Figure 1, for each cell in each recorded image the integrated fluorescence intensity, $I_{\mathrm{DNA}}$, was determined. The integrated fluorescence intensity corresponds to the area of the cell (determined from the transmission channel) times the mean fluorescence intensity from the Cy5 channel in that area. Fluorescence originating from the capsules was not considered, but only fluorescence located in the cytosol. The mean fluorescence intensities, as observed for the different ways of delivery, are displayed for incubation in: (a) serum-free, and in (b) serum-supplemented media together with the corresponding standard deviations. For each data point at least 30 cells were analyzed. The figure has been taken from reference [36]. Reprint with permission from Elsevier.

\subsubsection{Delivery of siRNA to block the expression of green fluorescence protein (GFP)}

In a further step within the same study [36], siRNA was used to transfect cells and to determine the efficacy of transfection with biodegradable capsules. For this purpose, GFP-expressing HeLa cells and siRNA capable of knocking out GFP were used. The cells were kept in serum-free medium for these 
experiments. The comparison here was made only between cells incubated with biodegradable siRNA-containing capsules and polyplexes. In Figure 3, images of the cells are shown. In this case, PEI was labeled with Dy-651 and colored in violet, and siRNA was labeled with AF-546 and colored in red. GFP is depicted in green. The left panel shows cells incubated with polyplexes and the right one cells incubated with polyplex-containing biodegradable capsules. The cells incubated with polyplexes kept their green fluorescence over the entire time, while in the images of cells incubated with capsules the fluorescence was lost after $30 \mathrm{~h}$ in the cells marked with asterisks $\left({ }^{*}\right)$. After $20 \mathrm{~h}$, the cells with capsules clearly showed distribution of PEI (violet) in the cytosol. The insets labeled with the number sign (\#) in the polyplex panel show that there is siRNA present in the cells (red label). These images were enhanced in contrast to make the red fluorescence visible.

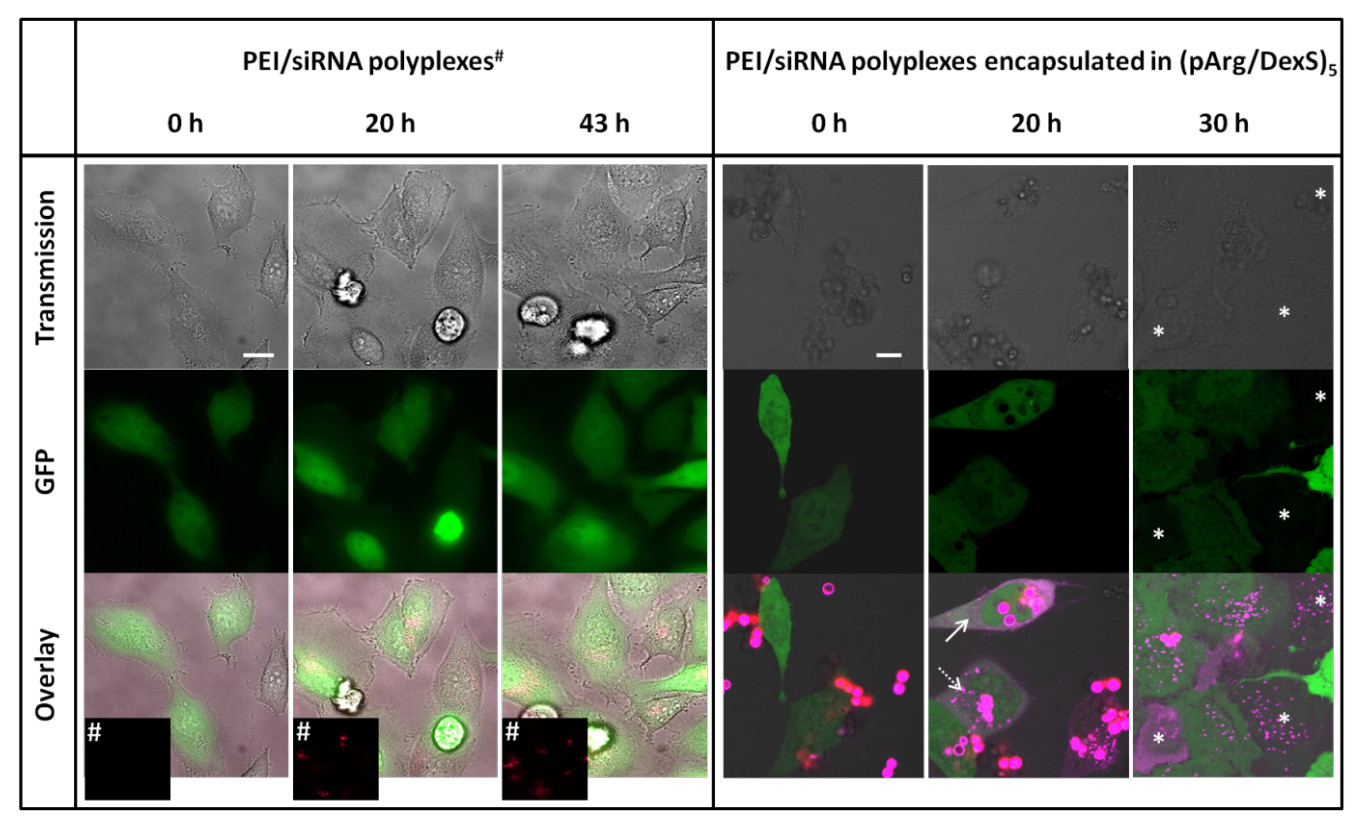

Figure 3. GFP-expressing HeLa cells were incubated with free (left column) and encapsulated (right column) PEI/siRNA polyplexes. Live images of the same cells were taken over time, $t$. Besides the transmission channel showing the cells, also GFP (green), AF-546 labeled siRNA (red), and DY-651 (violet) labeled PEI are displayed. The straight arrow indicates a homogenous cytosolic distribution of PEI, whereas the dashed arrow shows a punctuate distribution. Cells marked with asterisks have clearly lost their GFP fluorescence. The insets (\#) correspond to images of the polyplexes. For clarity, these insets were enhanced in contrast in order to show the presence of the siRNA inside the cells. The scale bars correspond to $10 \mu \mathrm{m}$. The figure has been taken from reference [36]. Reprint with permission from Elsevier. 
In Figure 4, the mean intensity is plotted against time for cells incubated with polyplexes, cells incubated with capsules, and untreated control cells. The amounts of siRNA added to the cells were comparable, $6.4 \cdot 10^{-3} \mu \mathrm{g}$ via capsules and $10 \cdot 10^{-3} \mu \mathrm{g}$ via polyplexes added to $2 \cdot 10^{4}$ seeded cells in $300 \mu \mathrm{L}$ of medium. The graph clearly shows that encapsulated polyplexes decrease the GFP fluorescence after $30 \mathrm{~h}$ of incubation. On the contrary, both polyplexes and control cells do not show any effect.

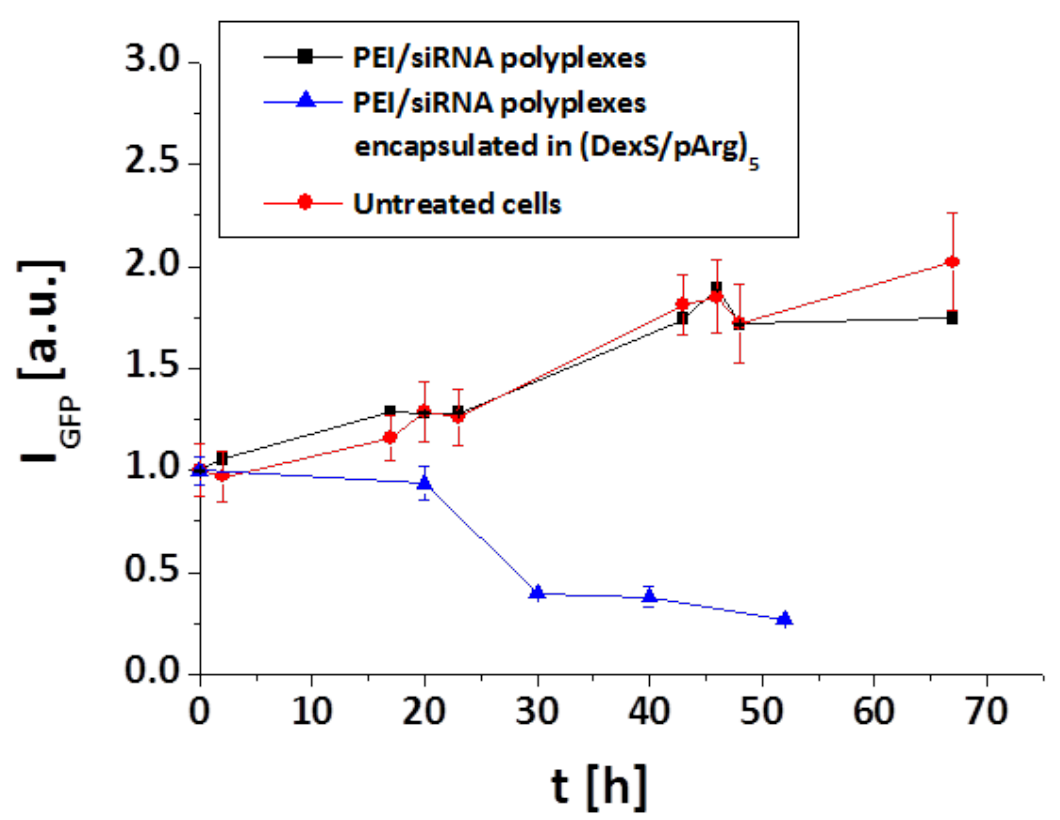

Figure 4. GFP-expressing HeLa cells were incubated with free encapsulated PEI/siRNA polyplexes. The total amount of siRNA and PEI was $6.4 \cdot 10^{-3} \mu \mathrm{g}$ and $25 \cdot 10^{-3} \mu \mathrm{g}$ for capsules and $10 \cdot 10^{-3} \mu \mathrm{g}$ and $12.5 \cdot 10^{-3} \mu \mathrm{g}$ for polyplexes, respectively. Images were taken at different points in time, $t$, and the mean integrated fluorescence density of GFP, i.e. the area of each cell times its mean fluorescence intensity, is displayed. The error bars represent standard deviations of the mean. The figure has been taken from reference [36]. Reprint with permission from Elsevier.

These results demonstrate that encapsulated polyplexes can be more efficient for the delivery of siRNA into cells than plain polyplexes. Furthermore, as already mentioned in the beginning of this paragraph, protection of the siRNA against degradation, high biocompatibility, and potentially controlled release of the cargo offer additional advantages of polymer capsules as delivery vehicles. 


\subsubsection{Cytotoxicity of PEI polyplexes and encapsulated PEI}

One concern not dealt with yet is the toxicity of PEI for cells, which has been described regularly for PEI polyplexes $[50,61,62]$. The capsules offer a way to reduce this problem, as they not only facilitate protection of siRNA against degradation but also protection for the cells from PEI. Ganas et al. verified this by a resazurin-based toxicity assay [36]. The results are depicted in Figure 5 as a function of added mass of PEI to make the experiments comparable.

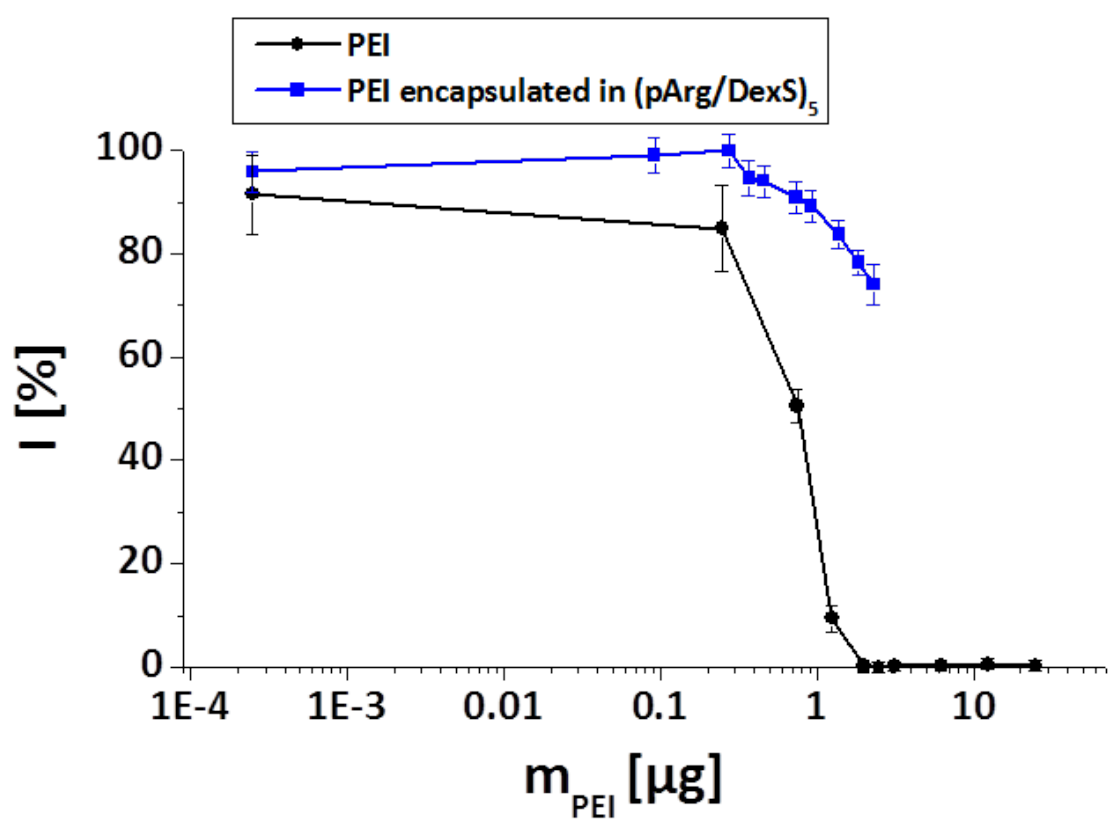

Figure 5. Reduction of cell viability caused by encapsulated and non-encapsulated PEI. The normalized cell viability in terms of resorufin fluorescence intensity, I, versus the amount of added PEI, $m_{\mathrm{PEI}}$, is displayed. The average of six (PEI capsules) and three

(PEI solution) independent measurements is displayed. Higher amounts of encapsulated PEI could not be measured as there is a threshold at which the capsules themselves can induce toxicity if added in too high quantities to the cells $[48,63]$. The error bars represent standard deviations of the mean. Note that the value for zero PEI could not be plotted due to the logarithmic scale but lies in the same range as the smallest plotted value. The figure has been taken from reference [36]. Reprint with permission from Elsevier.

For the capsules, larger amounts of PEI than plotted were not added to the cells because at some point the capsules themselves may introduce adverse effects $[48,63]$, and furthermore the cells do not have the capability to take up arbitrarily high numbers of capsules. Nonetheless, the graphs show that the toxicity of encapsulated PEI is much smaller than that of free PEI. The number 
of capsules added to the experiments corresponding to Figure 5 was 20 capsules per seeded cell, which accords to $25 \mathrm{ng}$ in the whole well. In the toxicity test, this accords to $0.1875 \mathrm{ng}$, as only $1.5 \cdot 10^{4}$ instead of $2 \cdot 10^{4}$ cells were seeded per well. At this amount, however, the viability of the cells is not affected. This means that the capsules protect the cells from the PEI of the encapsulated polyplexes [36].

\subsubsection{Light acting on Plasmonic nanoparticles as external trigger to mediate cargo release}

For light-triggered release, plasmonic nanoparticles can be integrated in the wall of the capsules. These nanoparticles can be excited with light at their plasmon frequency, inducing oscillations of the surface electrons, so-called plasmons. The plasmons subsequently transfer their energy first to the crystal lattice and from there to the environment, i.e. they dissipate heat [64-66]. The locally generated heat is sufficient to open the capsules and facilitate cargo release, not only from the capsule but also from the organelle [67-69]. Carregal-Romero et al. demonstrated this upon release of a $\mathrm{pH}$ sensor, which monitored differences in $\mathrm{pH}$ of the lysosomes and the cytosol along its way [68]. Moreover, more complex and labile molecules such as siRNA, mRNA or proteins can be released following this strategy while maintaining their performance [69]. Whereas in the previous paragraphs the release of nucleic acids was achieved making use of biodegradable capsules and the ability of PEI to trigger cytosolic release of the nucleic acids from the lysosomes [36], in this paragraph the release by external laser opening is described. This technique has the advantage that the release can be confined very specifically to a single cell and the capsule of interest. The release of macromolecules such as proteinencoding mRNA, but also proteins themselves is possible with this technique. In Figure 6, the burst of the lysosomal vesicle is shown [68]. Cells were incubated with seminaphtharhodafluor (SNARF)-containing light-responsive capsules. Before opening, the capsules appear in green-yellow due to the acidic lysosomal $\mathrm{pH}$. After irradiation with the laser, the capsules appear in yellow, indicating a neutral or slightly alkaline $\mathrm{pH}$ (Figure 6A). The images in A were taken with a low exposure time to image the capsules, whereas the images in $\mathrm{B}$ were taken with a high exposure time to detect the fluorescence in the cytosol, and thus the capsules appear overexposed in Figure 6B [68]. 


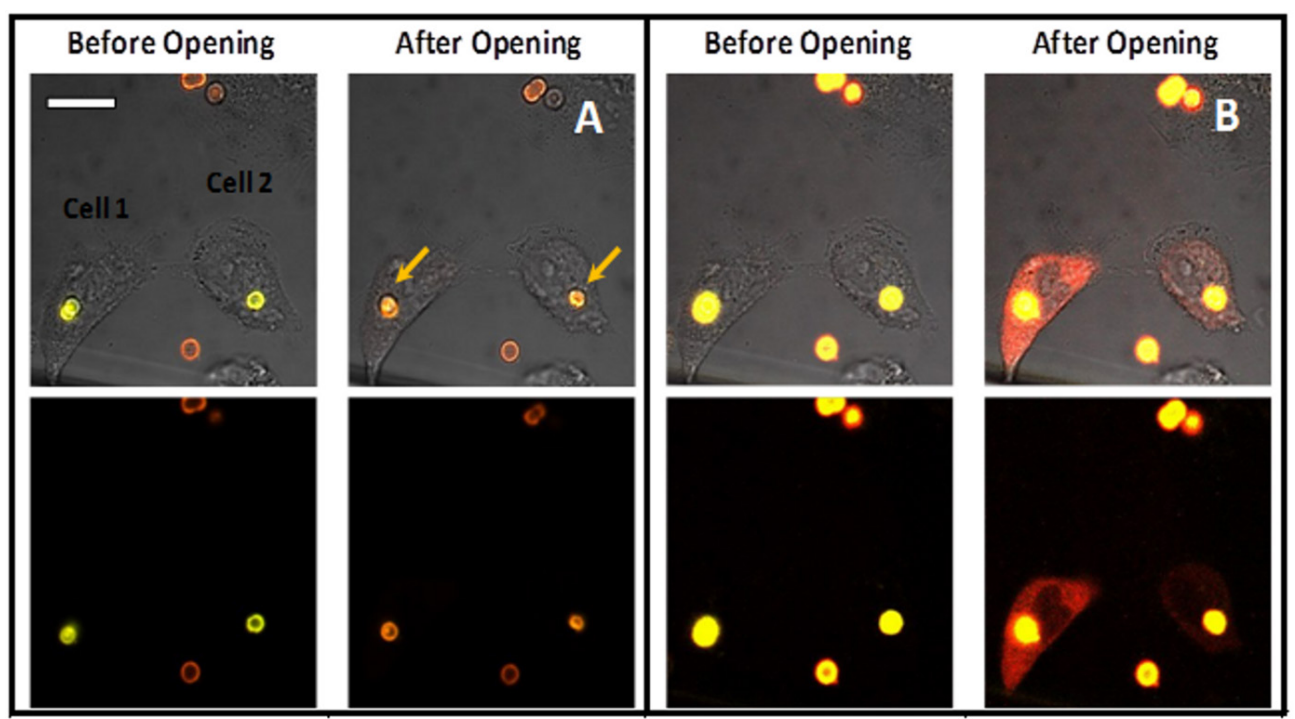

Figure 6. A549 cells were incubated with light-responsive SNARF-filled capsules. Before opening of the capsules, they appear in green-yellow indicating the acidic lysosomal $\mathrm{pH}$. After opening, the SNARF-dextran is released and spreads and the cytosol of the irradiated cells appears in red due to the neutral to slightly alkaline $\mathrm{pH}$. Images in A were taken with a small exposure time optimized to image the capsules; images in B were taken with a high exposure time in order to image the cytosol. Capsules in B therefore appear overexposed. The scale bar represents $20 \mu \mathrm{m}$. The figure has been taken from reference [68]. Reprint with permission from Elsevier.

\subsubsection{Delivery of $m R N A$ with light-responsive capsules}

Delivery of mRNA often is performed with polyplexes such as mentioned already above for the delivery of siRNA. The uptake and subsequent release of mRNA from the endocytic vesicles to the cytosol is statistically distributed. Determining the kinetics of cytosolic release is therefore difficult, as there is no clear starting point in time. Delivery of mRNA by light-responsive capsules in the contrary offers external control over the point in time of release and thus can circumvent this issue. In Figure 7, the kinetics of delivery of GFP-encoding mRNA is depicted for HeLa cells incubated with mRNA polyplexes on the left and mRNA-containing light-responsive capsules on the right side [69]. The kinetics of the polyplexes is plotted dependent on the incubation time showing saturation after $15 \mathrm{~h}$. The cells show a uniform expression of GFP as visible in the images after $10 \mathrm{~h}$ and $25 \mathrm{~h}$. The cells incubated with mRNA-delivering capsules show different kinetics. The expression possesses Gaussian distribution with the maximum at $10 \mathrm{~h}$ after the opening of the capsules. 
A)
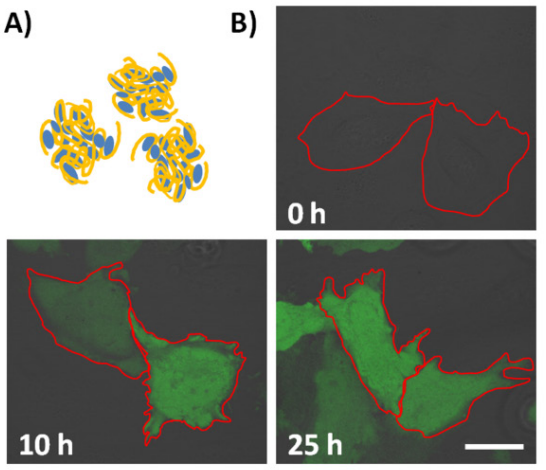

C)

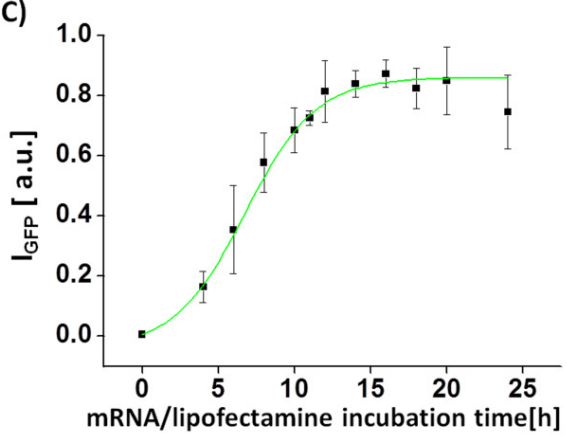

D)
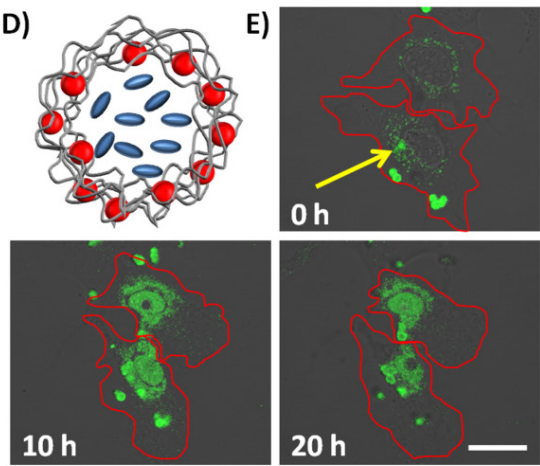

F)

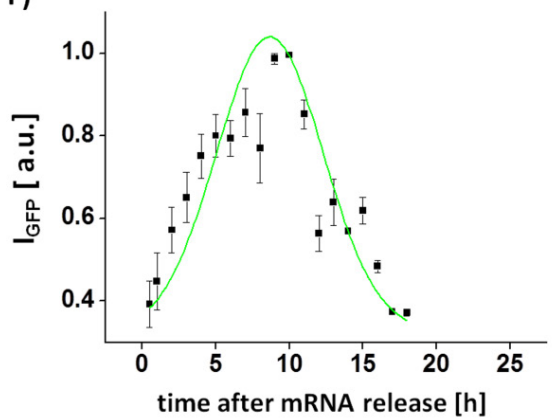

Figure 7. GFP expression of HeLa cells following transfection by polyplexes (left panel) and light-responsive capsules (right panel). (A) represents a sketch of polyplexes, (B) Confocal images of HeLa cells expressing GFP after treatment with polyplexes, C) mean fluorescence intensity of HeLa cells dependent on the incubation time, (D) a sketch of light-responsive capsules as carriers of mRNA, (E) confocal images of cells expressing GFP after treatment with light-responsive capsules, (F) time-dependent GFP intensity after light-mediated opening. The scale bars represents $20 \mu \mathrm{m}$. The figure has been taken from reference [69]. Reprint with permission from Wiley-VCH.

Controlling the beginning of release externally could offer a way to release mRNA of various proteins sequentially and study, for example, the interaction of different mRNAs or other cargos in a time-resolved manner independent of the uptake time and the time needed for cytosolic release. In order to demonstrate sequential release, Ochs et al. employed the phosphatase-mediated reaction of ELF97 phosphate to ELF97-alcohol [69]. Cells were co-incubated with light-responsive capsule filled with ELF97 phosphate or phosphatase, and a blue or red marker. The reaction could be taken out in cells containing capsules of both types. In Figure 8, the intracellular reaction is demonstrated once in the way that first phosphatase was released and only afterwards ELF97 phosphate (top panel), and once the other way around [69]. As visible in the images, the reaction product ELF97-alcohol sediments in the capsule opened secondly. The highest benefit from light-triggered release as described here can be taken for reactions of short timescale rather than for 
long-lasting systems, in which uptake and cytosolic release is negligible compared to the reaction itself.

\section{A) Phosphatase}
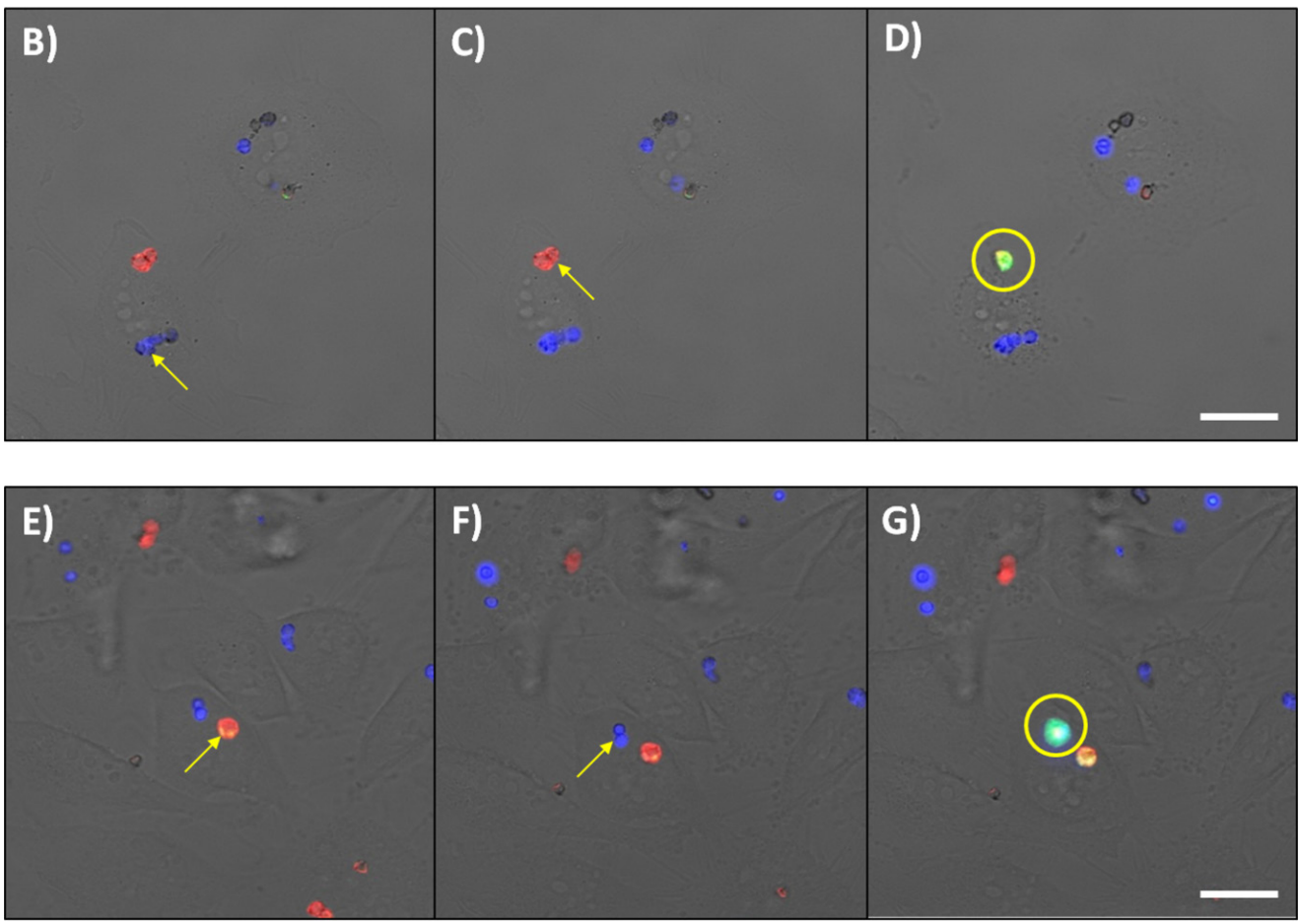

Figure 8. HeLa cells were incubated with light-responsive capsules containing nonfluorescent ELF97 phosphate and the red fluorescent AlexaFluor594-dextran (red capsules) and light-responsive capsules containing non-fluorescent phosphatase and the blue fluorescent Cascade Blue-dextran (blue capsules). Phosphatase is capable of converting ELF97 phosphate into fluorescent ELF97-alcohol (A). In a cell containing

both, ELF97 phosphate-filled capsule and phosphatase-filled capsule, first the phosphatase capsule is opened (B) and afterwards the ELF97 phosphate capsule (C). The enzymatic reaction takes place and the ELF97-alcohol's fluorescence is observable within the yellow circle (D). When first the ELF97 phosphate containing capsules and subsequently the phosphatase-containing capsules are opened (E-F), the ELF97alcohol sediments in the area of the phosphatase capsule (G). The scale bar corresponds to $25 \mu \mathrm{m}$. The figure has been taken from reference [69]. Reprint with permission from Wiley-VCH. 


\subsubsection{Protein release from light-responsive capsules}

Laser opening of capsules can also facilitate the release of the proteins themselves rather than the mRNA. In Figure 9, the release of GFP from capsules by laser irradiation is depicted [68]. After irradiation, the cytosol of the cells shows the green fluorescence of GFP, resulting from homogeneous spreading of the encapsulated GFP. In contrast, the GFP release from biodegradable capsules shows a dotted pattern indicating that GFP is located in small cellular vesicles, most likely exosomes.

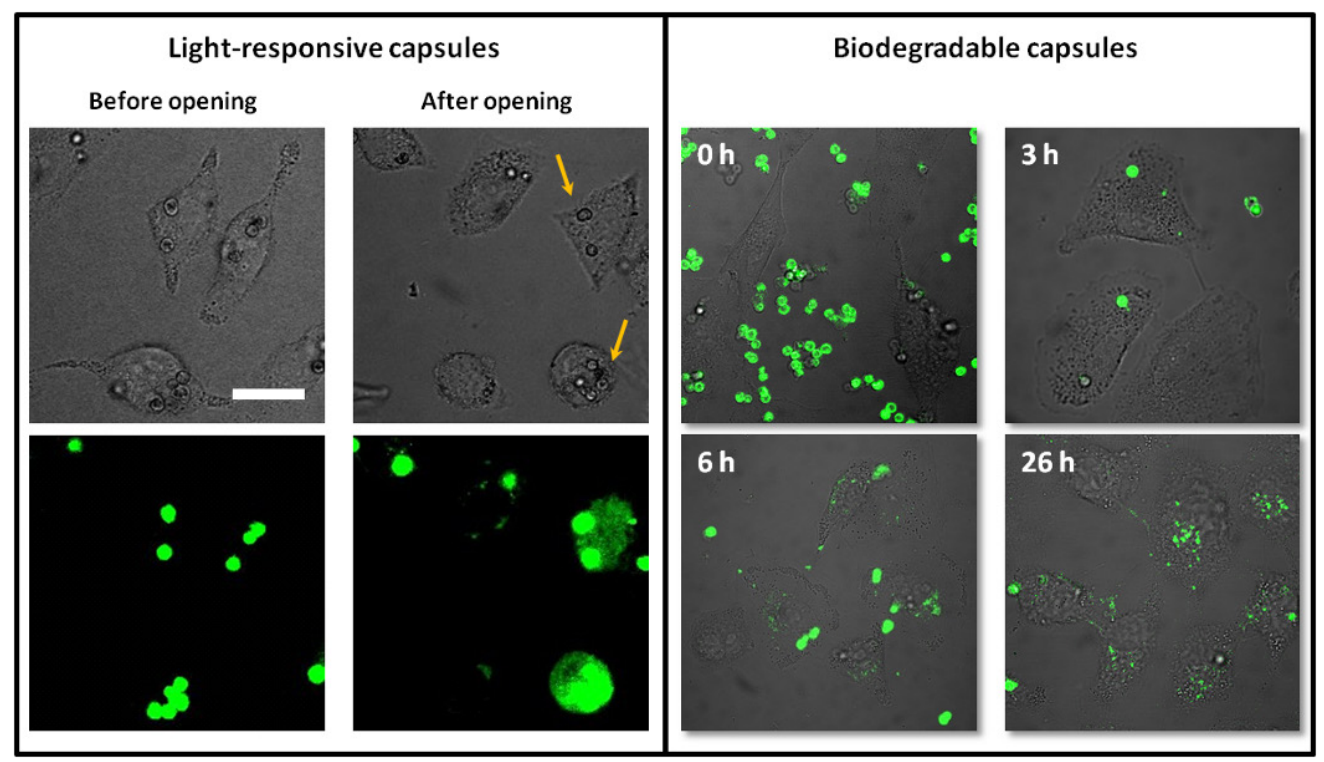

Figure 9. Release of GFP from light-responsive capsules in HeLa cells. The capsules were irradiated with a laser at intensity of $3.8 \mathrm{~mW} \mathrm{~cm}^{-2}$. Before irradiation the green fluorescence is confined to the capsules, afterwards the fluorescence is visible in the cytosol showing the release of GFP. The arrow points at the opened capsule. The scale bar corresponds to $20 \mu \mathrm{m}$. The figure has been taken from reference [68]. Reprint with permission from Elsevier. 


\subsection{APPLICATION II: SENSING}

\subsection{1. pH sensing with fluorescent dyes}

In the context of medical or pharmaceutical purposes, monitoring of the internal properties of a cell is of highest interest as many diseases are triggered by malfunctions of cells. In many cases, the homeostasis of the cells is influenced and alterations of intracellular properties can occur. One of the most fundamental properties in this manner is $\mathrm{pH}$. The activity of enzymes, for example, is dependent on $\mathrm{pH}$ and deviations from the appropriate $\mathrm{pH}$ lead to low activity and can in the worst case harm the enzyme irreversibly. Furthermore, $\mathrm{pH}$ gradients across cellular membranes play an important role, as they ensure that cells can extract energy from transport processes across membranes. $\mathrm{pH}$ monitoring in living cells can help to study proliferation, apoptosis, and endocytosis, among others [70-73]. Moreover, there are many examples of diseases where the $\mathrm{pH}$ regulation in the affected cells or tissue is disturbed $[74,75]$. Monitoring $\mathrm{pH}$ can therefore be used to identify affected cells or vice versa tell if a certain drug is capable of stopping the $\mathrm{pH}$ regulation disturbance. A straightforward way is to use cell-permeant forms of $\mathrm{pH}$ sensitive dyes, e.g. acetoxymethyl ester derivates. These dyes are electrically neutral and are taken up by cells via osmosis. Their signal is either a spectral shift upon change of $\mathrm{pH}$ or the emission intensity alters. As cellular fluids are very complex, there are many ways in which the dye can be influenced, e.g. by binding to proteins [76]. Therefore, to measure accurate $\mathrm{pH}$ values, the dye must be calibrated intracellularly. The most common way to do this is the use of nigericin, a $\mathrm{K}^{+} / \mathrm{H}^{+}$ionophore [77]. After treatment with nigericin, the intraand extracellular $\mathrm{pH}$ values equilibrate and the intracellular $\mathrm{pH}$ can be adjusted by change of the extracellular $\mathrm{pH}$. However, there are some problems associated with dye-based measurements. During long-time measurements, the cells sequester parts of the dye, which leads to lower signal, although no actual change of $\mathrm{pH}$ may have happened. Fading, also called photobleaching, is another issue in long-time experiments. In this case, repeated illumination leads to lower signal, due to reaction of the dye with radicals, e.g. reactive oxygen species, into non-fluorescent molecules [78,79]. Furthermore, a ratiometric measurement is preferred as it excludes sources of errors such as local gradients of the concentration of the dye, fluctuations of the illumination intensity over time, different exposure times, etc. [80,81]. For ratiometric measurements a second dye is needed as a reference, where the ratio of the local concentrations of the two dyes is constant and the ratio of the intensities is $\mathrm{pH}$-dependent, at least in the interesting $\mathrm{pH}$ range around $4.5-8$ for cells. 


\subsection{2. pH dependence of organic fluorophores}

Apart from protons, the most critical ions in cells are $\mathrm{Na}^{+}, \mathrm{K}^{+}, \mathrm{Ca}^{2+}, \mathrm{Mg}^{2+}$, and $\mathrm{Cl}^{-}$. The concentrations of $\mathrm{Na}^{+}, \mathrm{K}^{+}$, and $\mathrm{Cl}^{-}$are, for example, of special importance for muscle cells and neurons as the formation of action potentials is dependent on them. $\mathrm{Ca}^{2+}$ is important for the release of neurotransmitters and muscle contraction and can serve as cofactor for enzymes. $\mathrm{Mg}^{2+}$ also is a cofactor for many enzymes. The use of adenosintriphosphate (ATP) as energy source for the cell is, for example, only possible if magnesium is bound to the ATP. There are many organic fluorophores available for sensing and measuring intracellular concentrations of the mentioned ions. However, many of the dyes available tend to be $\mathrm{pH}$-sensitive in addition to respond to their specific ion and may also be sensitive to other ions [82]. For example, the potassium- and sodium-sensitive dyes, a fluorescent potassium-sensitive indicator (PBFI) and a fluorescent sodium-sensitive indicator (SBFI), respectively, show crosstalk with the correspondent other ion $[39,43]$, and the $\mathrm{Mg}^{2+}$-sensitive dye MagIndo-1 can also be used for sensing $\mathrm{Ca}^{2+}$. In Figure 10, the $\mathrm{pH}$ dependence of the chloride-sensitive dyes: $N$-(ethoxycarbonylmethyl])-6-methoxy-quinolinium bromide (MQAE) and 10,10'-bis(3-carboxypropyl)-9,9'-acridiniumdinitrate (BAC), the calcium sensor dye Calcium Green-1, and the magnesium sensor dye Mag-Indo-1 are reported by Kantner et al. [43].

a)

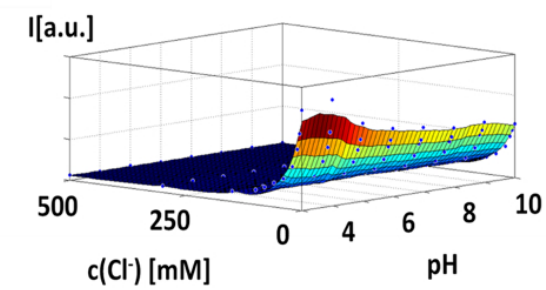

c)

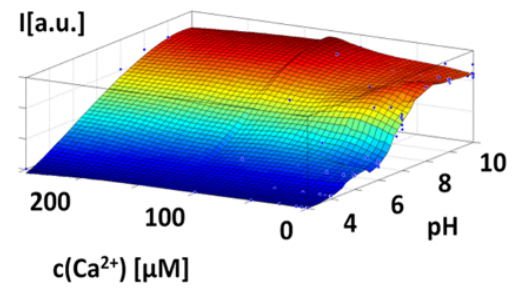

b)

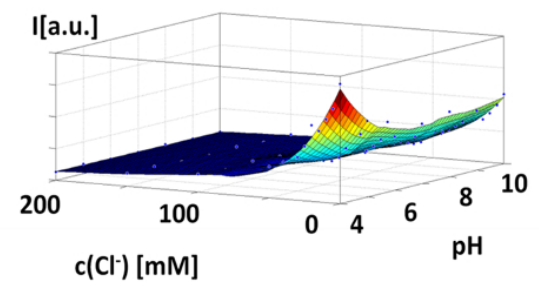

d)

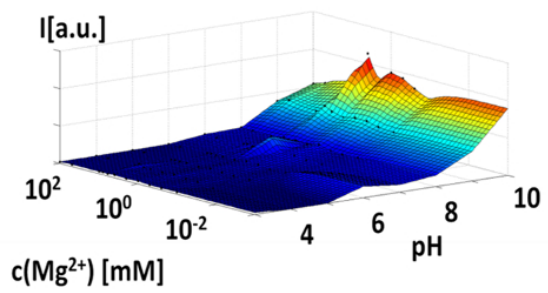

Figure 10. Response curves of ion-sensitive dyes to the respective ion and $\mathrm{pH}$.

Fluorescence signal of the chloride-sensitive dyes (a) MQAE and (b) BAC, in dependence of $\mathrm{Cl}^{-}$and $\mathrm{pH}$, (c) calcium-sensitive Calcium-green- 1 against $\mathrm{Ca}^{2+}$ and $\mathrm{pH}$, and (d) magnesium-sensitive Mag-Indo-1 in dependence of $\mathrm{Mg}^{2+}$ and $\mathrm{pH}$. In all cases, the signal intensity is clearly dependent on $\mathrm{pH}$ in addition to the respective ion. The

image is taken from reference [43]. Reprint with permission from Wiley-VCH. 
In all cases, the fluorescence intensity is clearly dependent on $\mathrm{pH}$. In the plots of the chloride-sensitive dyes, intensity values increase especially for low $\mathrm{pH}$ values, whereas for higher values, from $\mathrm{pH} 6-10$, the profile only slightly changes for constant chloride concentration. For the other two dyes, the fluorescence intensity is clearly dependent on $\mathrm{pH}$ as well. This means in principle that measurements with all these dyes need to be supported also by $\mathrm{pH}$ measurements to obtain clear results on changes of concentrations of the desired ions.

\subsubsection{Intracellular $\mathrm{pH}$ sensing with capsules}

As mentioned in the introduction, one application of capsules is their use as intracellular sensors. Thereby, advantage is taken of the porosity of the capsules, as small ions can virtually freely diffuse through the capsule walls [13], whereas the dye can be bound to bigger molecules such as dextran to keep it trapped inside the cavity. The use of capsules or other carriers has some advantages over the free dye. As the probe is confined to a small volume, the local concentration of the dye does not influence the measurement. For the free dye, problems can occur when the concentration of the dye is not evenly distributed as then the signal obtained is dependent on the concentration of the dye and on the concentration of the analyte [83]. Moreover, the capsules protect the dye from unspecific binding, sequestering, and degradation inside the cells [38]. Vice versa, the capsule also protects the cell from the dye. This opens the possibility to use molecules, which are toxic for the cells or have other undesired effects. To perform intracellular $\mathrm{pH}$-sensing with capsules, they were filled with the $\mathrm{pH}$-sensitive dye SNARF ${ }^{\circledR}$ bound to dextran. This dye is intrinsically ratiometric, as it has two emission maxima, one at $580 \mathrm{~nm}$, and one at $640 \mathrm{~nm}$. The maximum at $580 \mathrm{~nm}$ grows with decreasing $\mathrm{pH}$, whereas the one at $640 \mathrm{~nm}$ grows with increasing $\mathrm{pH}$. The ratio of both maxima can be used to obtain a calibration curve of the dye. In Figure 11a, the calibration curve for one batch of SNARF® capsules is depicted [41]. The capsules can be

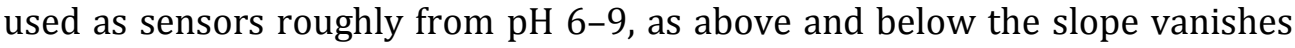
and hence the ratios cannot be related to a specific $\mathrm{pH}$ value anymore. In one recent report the SNARF ${ }^{\circledR}$ capsules were used as intracellular reporters for the lysosomal pH of MCF-7 breast cancer cells [41]. Capsules in the extracellular medium served as control capsules to confirm that changes of the color of the capsules did not take place automatically over time. In Figure 11, curves of intra- and extracellular capsules are plotted as function of time. The red line displays extracellular capsules and the green one internalized capsules. The ratio of the red and green intensity is plotted, which means that higher values correspond to higher $\mathrm{pH}$. The capsules were used now to monitor the lysosomal $\mathrm{pH}$ under influence of substances that are reported in the literature to influence the lysosomal or generally the cellular $\mathrm{pH}$. The substances tested were amiloride, bafilomycin $A_{1}$, chloroquine, and monensin. The mechanisms influencing the $\mathrm{pH}$ were of different nature. In this book chapter, we only 
describe the example of monensin; details for the other substances can be found in the publication and its supporting information [41]. Monensin is a $\mathrm{Na}^{+}$ ionophore, which means that it can bind to sodium ions and transport them through cell membranes. It is not specific to sodium ions but can bind also to potassium and other monovalent cations [84]. However, in cells it plays an important role as $\mathrm{Na}^{+} / \mathrm{H}^{+}$antiporter. This means that it transports sodium ions through membranes in one direction and protons in the other direction. Thereby, it abolishes sodium and $\mathrm{pH}$ gradients in the cells [85]. The capsules were calibrated in buffer solutions using fluorescence microscopy, Figure 11a [41]. The pH profile of untreated cells was obtained as control (Figure 11b) and the $\mathrm{pH}$ profile of cells treated with different substances was monitored. In Figure 11c, the plot of one monensin experiment is displayed. The yellow bar indicates the period when monensin was present. The red curves in a) and b) show photo-bleaching in the beginning. The green curve has a baseline slightly above one. The untreated cells do not change the $\mathrm{pH}$ over the time monitored. Cells treated with monensin show a rise in $\mathrm{pH}$ to that of the extracellular capsules very fast, indicating that the lysosomal and the extracellular $\mathrm{pH}$ equilibrate during the presence of monensin. The peak keeps a high level during the presence of monensin. As soon as there is equilibrium of $\mathrm{pH}$ and sodium ions across a membrane, a further increase of the $\mathrm{pH}$ value is not possible. This means that the equilibrium was reached within one hour. The fast decrease of the green curve after the washing supports this. By rinsing the cells, the effect of monensin is completely diminished within one hour.
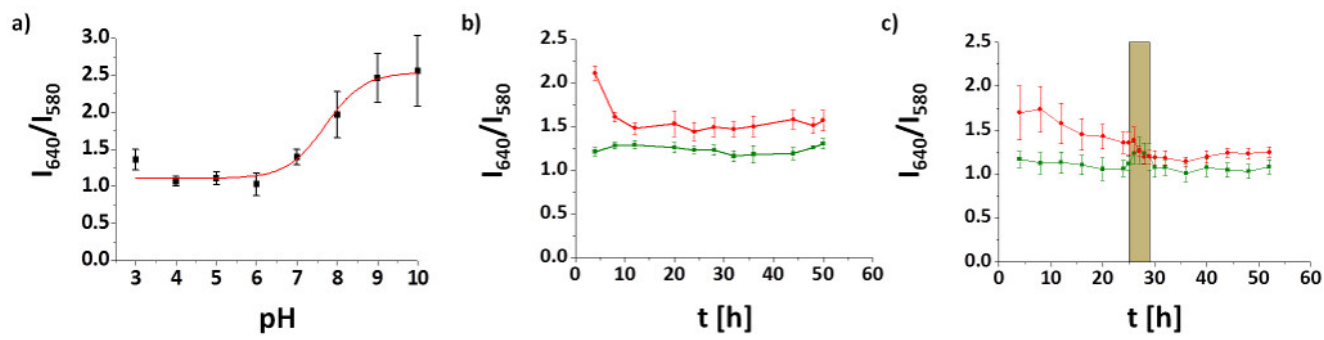

Figure 11. Monitoring the long-term behavior of the lysosomal pH of MCF-7 cells upon stimulation with monensin. The calibration curve (a) shows the applicability of the capsules for $\mathrm{pH}$ measurements from $\mathrm{pH}$ 6-9. In the control cells (b), no change of $\mathrm{pH}$ is observable. Cells treated with monensin (c) for $4 \mathrm{~h}$ (indicated by yellow bar) show increasing $\mathrm{pH}$ during the presence of monensin. The lysosomal $\mathrm{pH}$ reaches the level of the extracellular medium and returns to the basic value after removal of monensin. The image is taken from reference [41]. Reprint with permission from Wiley-VCH. 


\subsection{THERANOSTICS AS BIOMEDICAL APPROACH FOR POLYELECTROLYTE MULTILAYER CAPSULES}

One of the future goals in medical treatment is so-called personalized medicine [86]. This term describes the idea to customize treatment of different patients based on their individual condition. The treatment should involve the identification of the molecular factors of the disease and from this the appropriate treatment strategy should be chosen. Moreover, this approach is expected to reduce unnecessary treatment, as ineffective drugs and therapies are to be prevented by the identification of the specific disease markers. In a further step, the outcome of the treatment should be monitored, so to be able to respond to side effects [87]. The major example where personalized medicine is expected to improve treatment is cancer $[88,89]$. Theranostics is the term to describe the combination of therapy and diagnostics in one treatment $[90,91]$. Within this section we outline the advantages and possibilities of polymer capsules for use in both diagnosis and therapy. Diagnosis hereby is based on capsules as intracellular optical sensors (for example of $\mathrm{pH}$ due to their lysosomal location). There are numerous publications on optical sensors for intracellular ion sensing. However, very often there are also numerous shortcomings included [43,92]. In many articles, sensor systems are presented that show very good behavior in defined environment, for example buffers with varying concentration of the targeted ion. Yet, the claim that these sensors will work the same way intracellularly is often too strong, as the intracellular environment is in many aspects different from a simple buffer solution. Hence, a study presenting a sensor system but no proof that the sensors work inside cells is incomplete and should interpreted carefully. Studies including cell experiments often focus only on the proof that intracellular measurements are generally possible. Monitoring the behavior of the targeted ion concentration, however, is often excluded or only done over very short times [93,94]. Instead, it is important to also focus on the long-term monitoring of the dynamics of the lysosomal $\mathrm{pH}$ upon induced ion deregulation. $\mathrm{pH}$ is a preferential choice, as it is a ubiquitous quantity relevant for many cellular processes and because optical sensing of other ions is not as easy and straightforward as might be expected due to the $\mathrm{pH}$ dependence of many dyes as shown above [43]. Concerning therapy applications of capsules, integration of genetic material, i.e. DNA and RNA, into eukaryotic cells, the so-called gene therapy, was already shown as exemplary application previously in this chapter. Another therapeutic strategy in which capsules can be utilized is enzyme replacement therapy, for example in lysosomal storage diseases, will be discussed in the following. 


\subsubsection{Capsules for sensing and enzyme delivery in lysosomal storage disease models}

\subsubsection{Lysosomal storage disorders}

Polymer capsules are excellent candidates for the design of a theranostic tool to be applied in lysosomal storage disorders (LSD). Those disorders are a large family of rare diseases, which are characterized by defective enzymes in the lysosomes of one or more types of cells in the body [95-97]. So far, round about 50 LSDs are known. Each single disease is very rare in the population, but taken together makes for a rate of 1 in 4000-8000 live births [97]. Approved treatment is only available for six of these diseases so far and relies on socalled enzyme replacement therapy (ERT), in which the patients are administered the defective enzyme via intravenous infusion. The unfavorable outcome of these disorders is commonly death during the first years. The effect of the altered metabolization process on the lysosomal $\mathrm{pH}$ is not yet understood. As mentioned already, capsules are trafficked to the lysosomes of the cells after uptake. This opens the possibility for applications of capsules as carriers for the introduction of biologically active cargo into the lysosomes and at the same time live-monitoring the dynamics of $\mathrm{pH}$.

\subsubsection{Fabry disease}

One of the six diseases where treatment is available is Fabry disease. Patients with Fabry lack the enzyme $\alpha$-galactosidase A (GLA). This enzyme is responsible for the degradation of globotriaosylceramide (Gb3). There are two drugs approved for treatment, Replagal ${ }^{\circledR}$ from Shire and Fabrazyme ${ }^{\circledR}$ from Genzyme. However, there is need for improvement of these treatments for several reasons. First, so far the defective enzyme is injected as solution into the blood stream, which means that the enzyme is unprotected against degradation. This degradation already can happen in the body outside the cells, but also inside the cells the enzyme can be degraded before it begins its work in the lysosome [98]. The advantage of capsules is therefore the protection of the drug against degradation in the body. Second, GLA enters the cells through receptor-mediated uptake by mannose-6-phosphate receptors (M6PR). These receptors, however, may not be expressed homogeneously in all relevant organs of the patient, leading to imbalanced distribution of GLA in the body and thus ineffective treatment of the patient [95]. This can be evaded by use of capsules as shell, as capsule uptake is independent of receptors (in case there is no specific ligand attached to the capsule surface). Third, many patients begin to express antibodies against GLA and treatment becomes ineffective or inefficient $[95,99]$. The mechanism behind the immune response is the production of antibodies binding to GLA which can influence, among others, receptor binding and subcellular trafficking, which means that the enzymes might not reach the lysosomes anymore [99]. 


\subsection{Determination of GLA content of capsules by Western Blot}

Determination of capsule content is, in general, a difficult task. Absorption spectroscopy, for example, does not work properly as the capsules themselves usually absorb and scatter light much stronger than the cargo itself. Measuring the content of all washing solutions and subtracting the value from the amount used for synthesis is also highly error-prone. As the cargo in this case is a protein, Western Blot can be used to determine the content of the capsules. The exact mechanism why the capsules break and release their content is not clarified yet and to the best of our knowledge, Western Blots with polyelectrolyte capsules to determine the loading level have not been published so far. As the polyelectrolytes of the capsules are not covalently bound to each other, the electric field might rupture the capsules and subsequently, the content could be released. In so far unpublished work the amount of GLA per capsule found was approximately $400 \mathrm{fg}$ [100].

\subsection{Intracellular effect of GLA and GLA capsules}

GLA capsules were tested by Nazarenus et al. for their intracellular effectivity with mouse aorta endothelial cells (MAEC) from GLA knockout mice [100]. To determine the intracellular activity of the GLA capsules, the cells were coincubated with the capsules and the GLA substrate 7-nitrobenzofurazan (NBD)-labeled Gb3 (NBD-Gb3). The substrate is fluorescent while the product after conversion by GLA is non-fluorescent. Therefore, the intracellular activity of the capsules or free GLA can be obtained from the fluorescence of NBD-Gb3 in the cells. Concerns that the substrate is converted already in the cell medium before uptake by the cells can be ruled out as the enzyme only works well at acidic $\mathrm{pH}$ and thus only when it has reached the late endosomes or lysosomes in the cells. The efficiency of the capsules compared with GLA was determined by the fluorescence loss of NBD-Gb3. In Figure 12, the fluorescence loss is plotted against the mass concentration of GLA, which was calculated from the amount of GLA determined by Western Blot [100]. The amount administered with capsules was higher than that of the GLA solution. The curves show that the GLA solution has a higher efficacy, since already with a concentration of $1 \mathrm{mg} \mathrm{mL}^{-1}$ a fluorescence reduction of more than $90 \%$ was obtained, while the capsules do not reach such a high level, but only about $80 \%$. Furthermore, the GLA concentrations needed in case of capsules are higher than those in case of the GLA solution. 


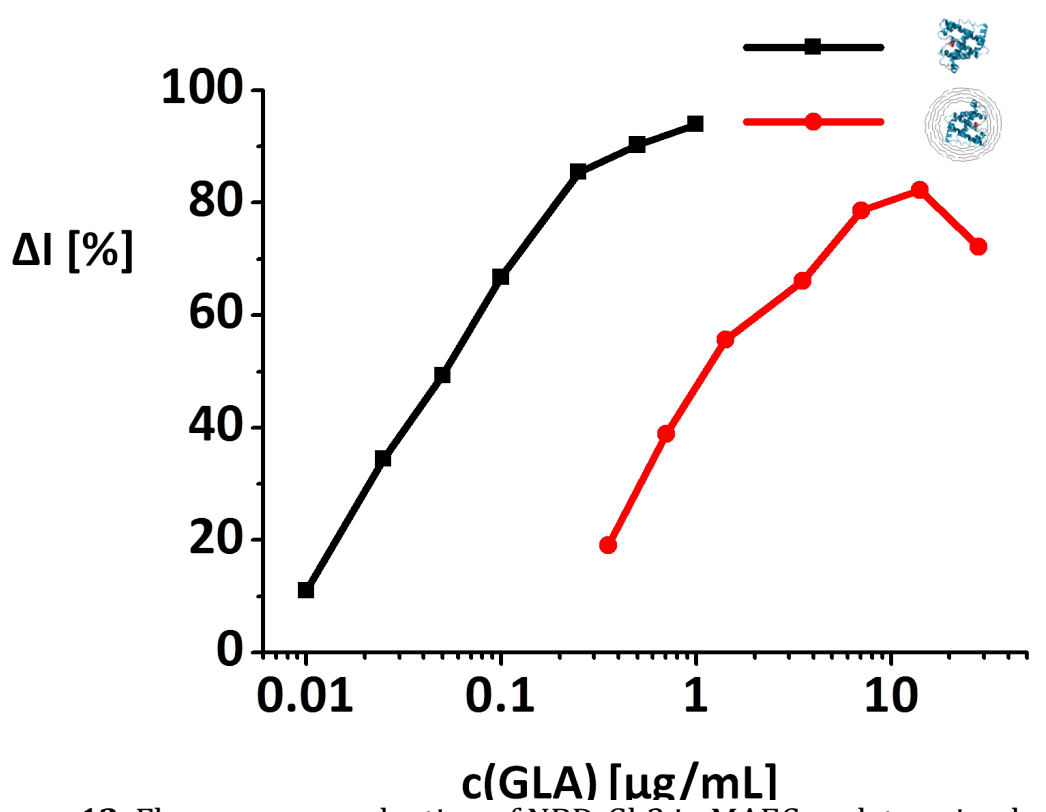

Figure 12. Fluorescence reduction of NBD-Gb3 in MAEC as determined with flow cytometry. The plot depicts the loss of fluorescence, $\Delta I$, as function of the administered concentration of GLA, either as solution (black curve) or as capsule suspension (red curve). Unpublished work [100].

\subsubsection{Krabbe disease}

Krabbe disease, also called globoid cell leukodystrophy, is an inherited neurological disorder. Knowledge about the disease is limited and so far no cure but only palliative and symptom-related treatment is available. Symptoms occur at the age of 3-6 months and involve fevers, limp stiffness, and decelerated mental and motor development among others. Later blindness and deafness can appear. The disease is triggered by a dysfunction of the oligodendrocytes of the patients. Oligodendrocytes are a type of brain cells, which provide the axons of neurons with an electrically insulating myelin sheath that also serves as scaffold. When the oligodendrocytes produce myelin, side products such as psychosine or other sphingolipids, and galactosylceramides are produced, which are metabolized by galactocerebrosidase (GALC). This enzyme is located in the lysosomes of the cells. In Krabbe disease, however, the oligodendrocytes lack this enzyme, and therefore, sphingolipids and galactosylceramides accumulate in the lysosomes. This accumulation leads to cell death, and subsequently, the axons are not provided their myelin sheath. The lack of insulation leads to slower signaling which can be measured in a nerve conduction study [101]. A simple model of Krabbe disease can be obtained from the M03.13 cell line [102,103]. These cells are immortalized oligodendrocytes. When incubated with psychosine 
they internalize and store it in lysosomes. In a so far unpublished study, the wild-type (MO3.13 WT) was used as well as cells where the enzyme GALC was knocked out (M03.13 KO) [100]. The knockout cells (KO) represent dysfunctional oligodendrocytes in the brain of Krabbe patients whereas the wild-type (WT) served as control.

\subsubsection{1. pH sensing in MO3.13 oligodentrocytes}

So far, there is not much knowledge about the influence of psychosine and other sphingolipids on the $\mathrm{pH}$ of oligodendrocytic cells and especially on cells lacking GALC. In so far unpublished work, SNARF® capsules were used to monitor the $\mathrm{pH}$ to obtain a time-resolved $\mathrm{pH}$ profile of the lysosomes during the accumulation of psychosine in both MO3.13 KO and M03.13 WT cells [100]. In Figure 13, the color change of one capsule in a WT cell is shown. The two images were taken within a period of $20 \mathrm{~min}$. The color changes from green to red, which shows that the local pH rose between those two images.

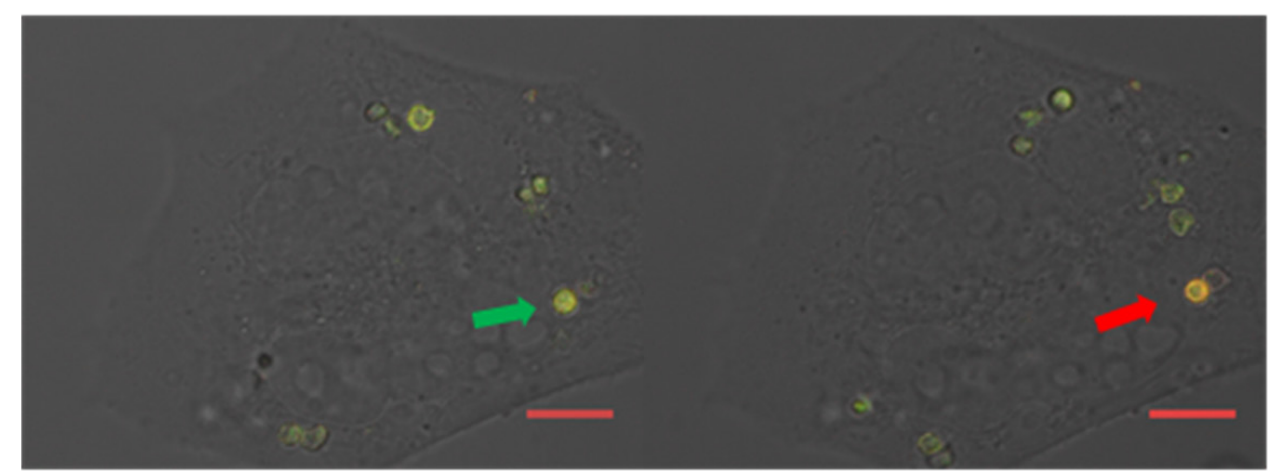

Figure 13. Example of a capsule where the color changes from green to red in a M03.13 WT cell. The scale bar corresponds to $10 \mu \mathrm{m}$. Unpublished work [100].

In Figure 14, images of cells incubated with $2 \mu \mathrm{M}$ psychosine are shown (a). The capsules appear in yellow due to the acidic environment of the lysosomes. Images of both WT and KO cells are depicted and "PSY" indicates cells incubated with psychosine whereas "Control" shows cells kept in psychosineand serum-free media. After $20 \mathrm{~h}$ of incubation, the cells in all the four conformations appear healthy and no sign of apoptosis is visible. Images like these were evaluated to obtain the time-resolved $\mathrm{pH}$ profile as seen on the right. A low-pass frequency filter was applied to the curves to abolish shortterm fluctuations and visualize the long-term trends more clearly. The blue lines represent the cells incubated with psychosine and the red lines the controls without psychosine. The graphs show that both the WT cells in (b) as well as the KO cells in (c) show small variations but no significant changes of $\mathrm{pH}$ during the presence of psychosine. Figure 15 contains images of M03.13 
cells incubated with $10 \mu \mathrm{M}$ of psychosine at different points in time. The marking is similar to Figure 14. Cells incubated with psychosine show round shapes after $600 \mathrm{~min}$, which is a sign of apoptosis. Both WT and KO cells show this behavior. In the KO cells, no significant color change is detectable, which is also true for both WT and KO controls. In the graphs, a significant difference between WT and KO cells is observable. While the KO cells in (b) do not show $\mathrm{pH}$ changes, the WT cells in a) show a clear rise in $\mathrm{pH}$ during the presence and accumulation of psychosine [100].

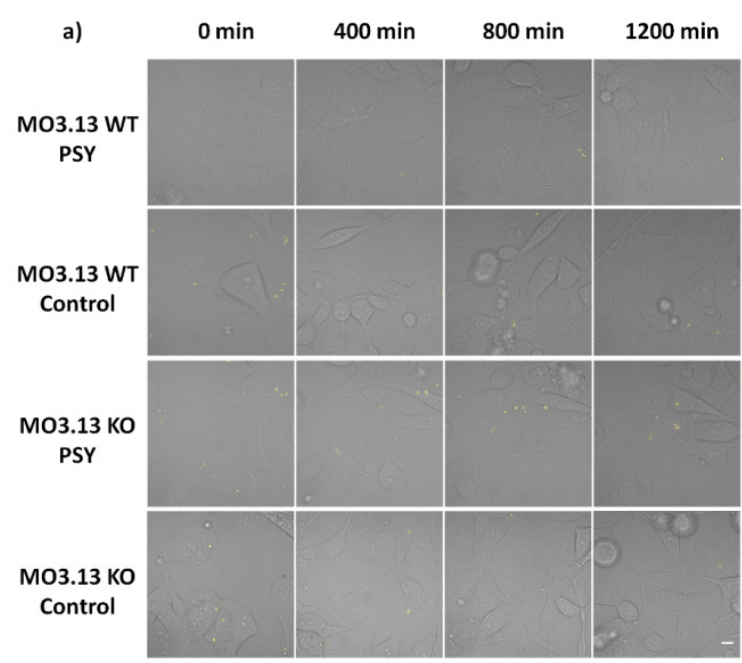

b)

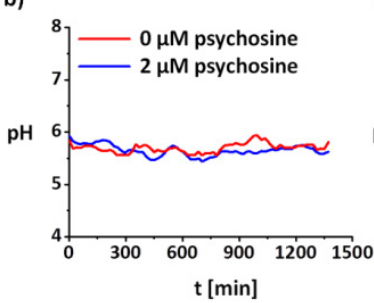

c)

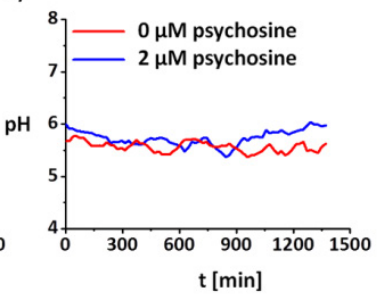

Figure 14. M03.13 cells incubated with psychosine at a concentration of $2 \mu \mathrm{M}$. (a) Images of the points in time indicated at the top are shown. "PSY" indicates the panels with cells incubated with psychosine, whereas "Control" indicates the cells in medium not supplemented with psychosine. From the images it can be seen that neither the WT nor the KO cells suffer from $2 \mu \mathrm{M}$ psychosine. SNARF ${ }^{\circledR}$ capsules in all images are yellow indicating the acidic $\mathrm{pH}$ environment of the lysosomes. The scale bar represents $10 \mu \mathrm{m}$.

(b) M03.13 cells treated with $2 \mu \mathrm{M}$ psychosine and controls without treatment. M03.13 WT cells (b) as well as M03.13 KO (c) cells show only small variations but no eminent change of lysosomal pH during incubation with $2 \mu \mathrm{M}$ of psychosine. Unpublished work [100]. 


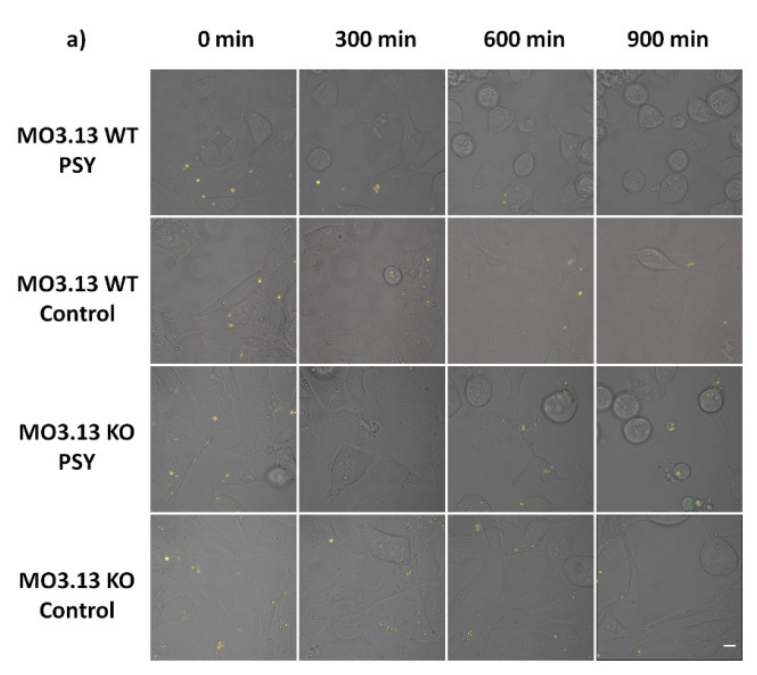

b)

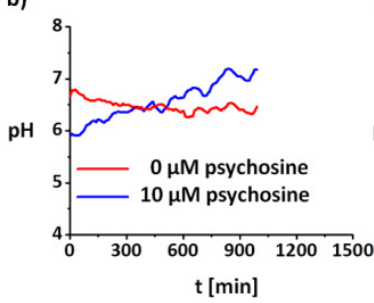

c)

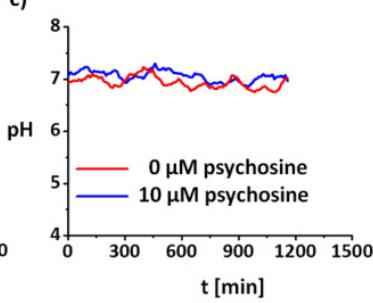

Figure 15. M03.13 cells incubated with psychosine at a concentration of $10 \mu \mathrm{M}$.

(a) Images of the points in time indicated at the top are shown. "PSY" indicates the panels with cells incubated with psychosine, whereas "Control" indicates the cells in medium not supplemented with psychosine. From the images it can be seen that both the WT and the KO cells suffer from $10 \mu \mathrm{M}$ psychosine as cells become round, which is a sign of apoptosis. SNARF ${ }^{\circledR}$ capsules in all images are yellow indicating the acidic $\mathrm{pH}$ environment of the lysosomes. The scale bar represents $10 \mu \mathrm{m}$. M03.13 WT cells show increase of the lysosomal $\mathrm{pH}$ during treatment with $10 \mu \mathrm{M}$ psychosine, whereas the control cells only show small variations (b). In contrary, M03.13 KO cells (c) only show

small variations of the lysosomal $\mathrm{pH}$ whether treated with psychosine or not. Unpublished work [100].

\subsection{Delivery of galactocerebrosidase to M03.13 oligodentrocytes}

So far, there is no drug to cure Krabbe disease. Other LSDs like Fabry or Gaucher can be treated by enzyme replacement therapy where the missing enzyme is delivered to the patients by intravenous infusion. Here, the idea was to introduce the lacking enzyme GALC into the cells by biodegradable capsules and scrutinize if the delivered enzyme could reduce the toxic effects of psychosine. As seen from the images in Figure 15, cells of the wild type as well as KO cells treated with $10 \mu \mathrm{M}$ of psychosine show signs of apoptosis after longer incubation times, i.e. the cells appear spherical [100]. This was 
quantified further by MTT cytotoxicity assays [100]. 5 or 10 GALC capsules, and in case of KO cells also 10 empty capsules per seeded cell were added to the cells together with the serum-free medium. Control cells without capsules were treated similarly. Afterwards, psychosine was added in serum-free medium at different concentrations from 0 to $20 \mu \mathrm{M}$. The results are found in Figure 16. The blue and black curves show the cells treated with capsules, the red curves the cells without capsules. The $100 \%$ value was always assigned to cells without capsules and without psychosine, i.e. the $0 \mu \mathrm{M}$ value of the red curves. In KO cells, the red curves show the same trend in both diagrams, and the black curve in (b), which represents empty capsules, shows the same behavior. KO cells incubated with GALC-containing capsules show high viability both with 5 and with 10 GALC capsules per seeded cell. The viability, however, is higher for cells treated with 5 capsules. With 10 capsules, the cells show a small loss in viability with rising psychosine concentration and generally lower viability. In WT cells, a contradictory behavior is observed, as shown in (c). The untreated cells show high viability independent of the concentration of psychosine, whereas cells incubated with capsules show clearly reduced viability, which means that the capsules have an adverse effect on the WT cells.
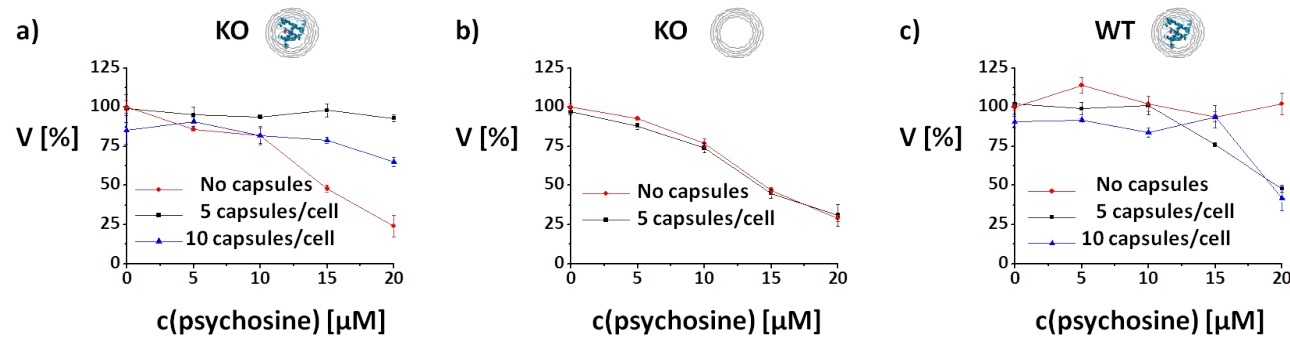

Figure 16. Viability test based on the chemical MTT (MTT assays) of MO3.13 KO cells. The viability, $V$, after $24 \mathrm{~h}$ is plotted versus the concentration of psychosine. The red curves represent cells without capsules whereas the black curves represent cells treated with (a) 5 GALC capsules per cell, (b) 10 GALC capsules per cell, and (c) 10 empty capsules per cell. The error bars represent standard deviations. Unpublished work [100]. 


\subsection{CONCLUSION}

Knowledge of intracellular ion distributions and concentrations is of high value for the diagnosis of diseases. Especially $\mathrm{pH}$ plays a prominent role. In general, the analysis of the entire intracellular ion milieu is of relevance for the health condition of cells. However, the intracellular measurements of other ions such as sodium, potassium, chloride, calcium, or magnesium, which are the most important ions for the cells, are problematic. The available ion-sensitive dyes usually are not only sensitive to the specific ion of interest but also show sensitivity to other ions and crosstalk with $\mathrm{pH}$. Therefore, $\mathrm{pH}$ is a very good parameter for diagnostic monitoring. The capsules thereby are a good choice of diagnostic tool as they are taken up by many different cell types, they are nontoxic, they allow non-invasive readout, and their intracellular stability allows for long-term monitoring. In the cited literature the usefulness of different sorts of capsules for therapeutic purposes was demonstrated. Regarding gene therapy, the delivery of RNA by biodegradable or by light-responsive capsules results in successful gene knockdown or gene expression, respectively. In case of biodegradable capsules, integrated PEI facilitates lysosomal escape due to the proton sponge effect. siRNA-filled biodegradable capsules have been demonstrated to enhance transfection efficacy compared to polyplexes as observable from the shorter transfection time of $20 \mathrm{~h}$ compared to $48 \mathrm{~h}$ in standard transfection protocols. Furthermore, the delivery can be performed in serum-supplemented medium. This is a big advantage over standard protocols, as deprivation of serum results in stress for the cells. This feature is especially important for in vivo experiments, where the serum levels cannot be regulated externally. In case of light-responsive capsules, the advantage of a distinct beginning time of transfection was shown. It is possible to open capsules with different cargos sequentially in the desired order and therefore study the interactions of various cargos in a time-resolved way. Another form of therapy addressable by capsules is enzyme replacement therapy. The introduction of proteins both by biodegradable and by light-responsive capsules is possible. In case of the biodegradable capsules, one can make use of the natural uptake route of capsules terminating in the lysosomes of the cells. Models of lysosomal storage disorders were used to demonstrate the successful delivery of deficient enzymes to the respective cells. The functionality of the delivered enzymes was shown in models for Krabbe and Fabry disease. In case of the light-responsive capsules, the successful introduction into the cells was demonstrated with the phosphatase-mediated reaction of ELF-97 phosphate to ELF-97-alcohol, as well as the release of GFP from the capsules into the cytosol. 


\section{REFERENCES}

1. F. Caruso, R.A. Caruso, H. Möhwald. Science 282 (1998) 1111-1114.

2. E. Donath, G.B. Sukhorukov, F. Caruso, S.A. Davis, H. Möhwald. Angew. Chem. Int. Ed. 37 (1998) 2202-2205.

3. A. Yashchenok, B. Parakhonskiy, S. Donatan, D. Kohler, A. Skirtach, H. Mohwald. J. Mater. Chem. B 1 (2013) 1223-1228.

4. J.W. Cui, M.P. van Koeverden, M. Mullner, K. Kempe, F. Caruso. Adv. Colloid Interface Sci. 207 (2014) 14-31.

5. B. Neu, A. Voigt, R. Mitlohner, S. Leporatti, C.Y. Gao, E. Donath, H. Kiesewetter, H. Mohwald, H.J. Meiselman, H. Baumler. J. Microencapsul. 18 (2001) 385-395.

6. O. Kreft, R. Georgieva, H. Baumler, M. Steup, B. Muller-Rober, G.B. Sukhorukov, H. Mohwald. Macromol. Rapid Commun. 27 (2006) 435-440.

7. S. De Koker, T. Naessens, B.G. De Geest, P. Bogaert, J. Demeester, S. De Smedt, J. Grooten. J. Immunol. 184 (2010) 203-211.

8. $\quad$ P. Rivera Gil, S.D. Koker, B.G. De Geest, W.J. Parak. Nano Lett. 9 (2009) 4398-4402.

9. B.G. De Geest, N.N. Sanders, G.B. Sukhorukov, J. Demeester, S.C. De Smedt. Chem. Soc. Rev. 36 (2007) 636-649.

10. Z. She, M.N. Antipina, J. Li, G.B. Sukhorukov. Biomacromolecules 11 (2010) 1241-1247.

11. U. Shimanovich, G.J.L. Bernardes, T.P.J. Knowles, A. Cavaco-Paulo. Chem. Soc. Rev. 43 (2014) 1361-1371.

12. A. Musyanovych, K. Landfester. Macromol. Biosci. 14 (2014) 458-477.

13. S. Carregal-Romero, P. Rinklin, S. Schulze, M. Schäfer, A. Ott, D. Hühn, X. Yu, B. Wolfrum, K.-M. Weitzel, W.J. Parak. Macromol. Rapid Commun. 34 (2013) 1820-1826.

14. M.D. Miller, M.L. Bruening. Langmuir 20 (2004) 11545-11551.

15. M.D. Miller, M.L. Bruening. Chem. Mater. 17 (2005) 5375-5381.

16. D. Halozan, G.B. Sukhorukov, M. Brumen, E. Donath, H. Möhwald. Acta Chim. Slov. 54 (2007) 598-604.

17. G.B. Sukhorukov, M. Brumen, E. Donath, H. Möhwald. J. Phys. Chem. B 103 (1999) 6434-6440.

18. G. Ibarz, L. Dahne, E. Donath, H. Mohwald. Chem. Mater. 14 (2002) 4059-4062.

19. G. Ibarz, L. Dahne, E. Donath, H. Mohwald. Macromol. Rapid Commun. 23 (2002) 474-478.

20. M. Schönhoff, V. Ball, A.R. Bausch, C. Dejugnat, N. Delorme, K. Glinel, R.V. Klitzing, R. Steitz. Colloids Surf., A 303 (2007) 14-29.

21. M. Lösche, J. Schmitt, G. Decher, W.G. Bouwman, K. Kjaer. Macromolecules 31 (1998) 8893-8906.

22. J.E. Wong, F. Rehfeldt, P. Hänni, M. Tanaka, R.v. Klitzing. Macromolecules 37 (2004) 7285-7289.

23. S.B. Abbott, W.M. de Vos, L.L.E. Mears, R. Barker, R.M. Richardson, S.W. Prescott. Macromolecules 47 (2014) 3263-3273.

24. L.L. del Mercato, M.M. Ferraro, F. Baldassarre, S. Mancarella, V. Greco, R. Rinaldi, S. Leporatti. Adv. Colloid Interface Sci. 207 (2014) 139-154.

25. S. Carregal-Romero, M. Ochs, W.J. Parak. Nanophotonics 1 (2012) 171-180. 
26. S. De Koker, B.G. De Geest, S.K. Singh, R. De Rycke, T. Naessens, Y. Van Kooyk, J. Demeester, S.C. De Smedt, J. Grooten. Angew. Chem. Int. Ed. 48 (2009) 8485-8489.

27. L. Kastl, D. Sasse, V. Wulf, R. Hartmann, J. Mircheski, C. Ranke, S. CarregalRomero, J.A. Martínez-López, R. Fernández-Chacón, W.J. Parak, H.-P. Elsaesser, P. Rivera Gil. ACS Nano 7 (2013) 6605-6618.

28. S. De Koker, B.G. De Geest, C. Cuvelier, L. Ferdinande, W. Deckers, W.E. Hennink, S. De Smedt, N. Mertens. Adv. Funct. Mater. 17 (2007) 3754-3763.

29. O. Shimoni, Y. Yan, Y. Wang, F. Caruso. ACS Nano 7 (2013) 522-530.

30. Y. Yan, M. Bjornmalm, F. Caruso. Chem. Mater. 26 (2014) 452-460.

31. Y. Yan, Z.W. Lai, R.J.A. Goode, J. Cui, T. Bacic, M.M.J. Kamphuis, E.C. Nice, F. Caruso. ACS Nano 7 (2013) 5558-5567.

32. Z.J. Wang, L. Qian, X.L. Wang, H. Zhu, F. Yang, X.R. Yang. Colloids Surf., A 332 (2009) 164-171.

33. T. Borodina, E. Markvicheva, S. Kunizhev, H. Moehwald, G.B. Sukhorukov, O. Kreft. Macromol. Rapid Commun. 28 (2007) 1894-1899.

34. O.E. Selina, S.Y. Belov, N.N. Vlasova, V.I. Balysheva, A.I. Churin, A. Bartkoviak, G.B. Sukhorukov, E.A. Markvicheva. Russ. J. Bioorg. Chem. 35 (2009) 103-110.

35. J. Ruesing, O. Rotan, C. Gross-Heitfeld, C. Mayer, M. Epple. J. Mater. Chem. B 2 (2014) 4625-4630.

36. C. Ganas, A. Weiß, M. Nazarenus, S. Rösler, T. Kissel, P. Rivera-Gil, W.J. Parak. J. Control. Release 196 (2014) 132-138.

37. S. De Koker, R. Hoogenboom, B.G. De Geest. Chem. Soc. Rev. 41 (2012) 2867-2884.

38. $\quad$ L.L. del Mercato, A.Z. Abbasi, W.J. Parak. Small 7 (2011) 351-363.

39. L.L. del Mercato, A.Z. Abbasi, M. Ochs, W.J. Parak. ACS Nano 5 (2011) 9668-9674.

40. O. Kreft, A. Muñoz Javier, G.B. Sukhorukov, W.J. Parak. J. Mater. Chem. 17 (2007) 4471-4476.

41. P. Rivera Gil, M. Nazarenus, S. Ashraf, W.J. Parak. Small 8 (2012) 943-948.

42. U. Resch-Genger, M. Grabolle, S. Cavaliere-Jaricot, R. Nitschke, T. Nann. Nat. Methods 5 (2008) 763-775.

43. K. Kantner, S. Ashraf, S. Carregal-Romero, C. Carrillo-Carrion, M. Collot, P. del Pino, W. Heimbrodt, D. Jimenez de Aberasturi, U. Kaiser, L.I. Kazakova, M. Lelle, N. Martinez de Baroja, J.-M. Montenegro, M. Nazarenus, B. Pelaz, K. Peneva, P. Rivera Gil, N. Sabir, L.M. Schneider, L.I. Shabarchina, G.B. Sukhorukov, M. Vazquez, F. Yang, W.J. Parak. Small 11 (2015) 896-904.

44. L.I. Kazakova, L.I. Shabarchina, G.B. Sukhorukov. Phys. Chem. Chem. Phys. 13 (2011) 11110-11117.

45. T. Saxl, F. Khan, D.R. Matthews, Z.L. Zhi, O. Rolinski, S. Ameer-Beg, J. Pickup. Biosens. Bioelectron. 24 (2009) 3229-3234.

46. P.K. Harimech, R. Hartmann, J. Rejman, P. del Pino, P. Rivera Gil, W.J. Parak. J. Mater. Chem. $B 3$ (2015) 2801-2807.

47. R. Palankar, B.-E. Pinchasik, S. Schmidt, B.G. De Geest, A. Fery, H. Möhwald, A. Skirtach, M. Delcea. J. Mater. Chem. B 1 (2013) 1175-1181.

48. B.G. De Geest, G.B. Sukhorukov, H. Mohwald. Exp. Opin. Drug Deliv. 6 (2009) 613-624.

49. [49] G. Creusat, A.S. Rinaldi, E. Weiss, R. Elbaghdadi, J.S. Remy, R. Mulherkar, G. Zuber. Bioconjugate Chem. 21 (2010) 994-1002. 
50. A. Zintchenko, A. Philipp, A. Dehshahri, E. Wagner. Bioconjugate Chem. 19 (2008) 1448-1455.

51. E. Wagner. Acc. Chem. Res. 45 (2012) 1005-1013.

52. J.P. Behr. Chimia 51 (1997) 34-36.

53. N.D. Sonawane, F.C. Szoka Jr., A.S. Verkman. J. Biol. Chem. 278 (2003) 44826-44831.

54. K. Pike-Overzet, M. van der Burg, G. Wagemaker, J.J. van Dongen, F.J. Staal. Mol. Ther. 15 (2007) 1910-1916.

55. S. Han, R.I. Mahato, Y.K. Sung, S.W. Kim. Mol. Ther. 2 (2000) 302-317.

56. A. Schambach, D. Zychlinski, B. Ehrnstroem, C. Baum. Hum. Gene Ther. 24 (2013) 132-142.

57. S. De Koker, L.J. De Cock, P. Rivera Gil, W.J. Parak, R.A. Velty, C. Vervaet, J.P. Remon, J. Grooten, B.G. De Geest. Adv. Drug Deliv. Rev. 63 (2011) 748-761.

58. A.L. Becker, N.I. Orlotti, M. Folini, F. Cavalieri, A.N. Zelikin, A.P.R. Johnston, N. Zaffaroni, F. Caruso. ACS Nano 5 (2011) 1335-1344.

59. N. Toub, J.R. Bertrand, A. Tamaddon, H. Elhamess, H. Hillaireau, A. Maksimenko, J. Maccario, C. Malvy, E. Fattal, P. Couvreur. Pharm. Res. 23 (2006) 892-900.

60. Invitrogen, Stealth ${ }^{\mathrm{TM}} / \mathrm{siRNA}$ Transfection Protocol Lipofectamine ${ }^{\circledR} 2000$, http://www.lifetechnologies.com/de/de/home/references/protocols/cellculture/transfection-protocol/stealth-sirna-transfection-lipofectamine.html (08 May 2014).

61. O.M. Merkel, A. Beyerle, B.M. Beckmann, M.Y. Zheng, R.K. Hartmann, T. Stoger, T.H. Kissel. Biomaterials 32 (2011) 2388-2398.

62. S.M. Sparks, C.L. Waite, A.M. Harmon, L.M. Nusblat, C.M. Roth, K.E. Uhrich. Macromol. Biosci. 11 (2011) 1192-1200.

63. C. Kirchner, A.M. Javier, A.S. Susha, A.L. Rogach, O. Kreft, G.B. Sukhorukov, W.J. Parak. Talanta 67 (2005) 486-491.

64. A.G. Skirtach, C. Dejugnat, D. Braun, A.S. Susha, W.J. Parak, H. Möhwald, G.B. Sukhorukov. Nano Lett. 5 (2005) 1371-1377.

65. B. Radt, T.A. Smith, F. Caruso. Adv. Mater. 16 (2004) 2184-2189.

66. A.S. Angelatos, B. Radt, F. Caruso. J. Phys. Chem. B 109 (2005) 3071-3076.

67. A.G. Skirtach, A.M. Javier, O. Kreft, K. Köhler, A.P. Alberola, H. Möhwald, W.J. Parak, G.B. Sukhorukov. Angew. Chem. Int. Ed. 45 (2006) 4612-4617.

68. S. Carregal-Romero, M. Ochs, P. Rivera Gil, C. Ganas, A.M. Pavlov, G.B. Sukhorukov, W.J. Parak. J. Control. Release 159 (2012) 120-127.

69. M. Ochs, S. Carregal-Romero, J. Rejman, K. Braeckmans, S.C. De Smedt, W.J. Parak. Angew. Chem. Int. Ed. 52 (2013) 695-699.

70. D. Lagadic-Gossmann, L. Huc, V. Lecureur. Cell Death Differ. 11 (2004) 953-961.

71. H. Sakai, G. Li, Y. Hino, Y. Moriura, J. Kawawaki, M. Sawada, M. Kuno. J. Physiol. London 591 (2013) 5851-5866.

72. S.D. Freedman, H.F. Kern, G.A. Scheele. Eur. J. Cell Biol. 75 (1998) 153-162.

73. P. Cosson, I. Decurtis, J. Pouyssegur, G. Griffiths, J. Davoust. J. Cell Biol. 108 (1989) 377-387.

74. P. Swietach, R.D. Vaughan-Jones, A.L. Harris, A. Hulikova. Philos. Trans. R. Soc. B. 369 (2014) 20130099.

75. A. Rivinoja, F.M. Pujol, A. Hassinen, S. Kellokumpu. Ann. Med. 44 (2012) 542-554. 
76. O. Seksek, N. Henrytoulme, F. Sureau, J. Bolard. Anal. Biochem. 193 (1991) 49-54.

77. J. Bond, J. Varley. Cytom. Part A 64A (2005) 43-50.

78. A. Longin, C. Souchier, M. French, P.A. Bryon. J. Histochem. Cytochem. 41 (1993) 1833-1840.

79. L.L. Song, E.J. Hennink, I.T. Young, H.J. Tanke. Biophys. J. 68 (1995) 2588-2600.

80. M.J. Marin, F. Galindo, P. Thomas, D.A. Russell. Angew. Chem. Int. Ed. 51 (2012) 9657-9661.

81. E.S. Childress, C.A. Roberts, D.Y. Sherwood, C.L.M. LeGuyader, E.J. Harbron. Anal. Chem. 84 (2012) 1235-1239.

82. F.A. Lattanzio, D.K. Bartschat. Biochem. Biophys. Res. Commun. 177 (1991) 184-191.

83. J.Y. Han, K. Burgess. Chem. Rev. 110 (2010) 2709-2728.

84. M. Pinkerton, L.K. Steinrau. J. Mol. Biol. 49 (1970) 533-546.

85. K.A. Schmitz, D.L. Holcomb-Wygle, D.J. Oberski, C.B. Lindemann. Biophys. J. 79 (2000) 468-478.

86. L. Hood, J.R. Heath, M.E. Phelps, B.Y. Lin. Science 306 (2004) 640-643.

87. F. Pene, E. Courtine, A. Cariou, J.P. Mira. Crit. Care Med. 37 (2009) S50-S58.

88. J.K. Kim, K.J. Choi, M. Lee, M.H. Jo, S. Kim. Biomaterials 33 (2012) 207-217.

89. V.I. Shubayev, T.R. Pisanic, S.H. Jin. Adv. Drug Deliv. Rev. 61 (2009) 467-477.

90. P. Prabhu, V. Patravale. J. Biomed. Nanotechnol. 8 (2012) 859-882.

91. R. Kumar, A. Kulkarni, D.K. Nagesha, S. Sridhar. Theranostics 2 (2012) 714-722.

92. M. Nazarenus, Q. Zhang, M.G. Soliman, P. del Pino, B. Pelaz, S. Carregal Romero, J. Rejman, B. Rothen-Ruthishauser, M.J.D. Clift, R. Zellner, G.U. Nienhaus, J.B. Delehanty, I.L. Medintz, W.J. Parak. Beilstein J. Nanotechnol. 5 (2014) 1477-1490.

93. A.M. Dennis, W.J. Rhee, D. Sotto, S.N. Dublin, G. Bao. ACS Nano 6 (2012) 2917-2924.

94. A. Orte, J.M. Alvarez-Pez, M.J. Ruedas-Rama. ACS Nano 7 (2013) 6387-6395.

95. S. Muro. WIRES Nanomed. Nanobi. 2 (2010) 189-204.

96. R.M.N. Boustany. Nat. Rev. Neurol. 9 (2013) 583-598.

97. S. Ortolano, I. Vieitez, C. Navarro, C. Spuch. Recent Pat. Endocr. Metab. Immune Drug Discov. 8 (2014) 9-25.

98. S. Mumtaz, B.K. Bachhawat. Biochim. Biophys. Acta 1199 (1994) 175-182.

99. P.B. Deegan. J. Inherit. Metab. Dis. 35 (2012) 227-243.

100. M. Nazarenus, I. Abasolo, N. García Aranda, V. Voccoli, J. Rejman, S. Schwartz Jr., M. Cecchini, P. Rivera Gil, W.J. Parak. Unpublished Work.

101. M.B. Weimer, A. Gutierrez, G.B. Baskin, J.T. Borda, R.S. Veazey, L. Myers, K.M. Phillippi-Falkenstein, B.A. Bunnell, M.S. Ratterree, J.D. England. Muscle Nerve 32 (2005) 185-190.

102. E. Haq, S. Giri, I. Singh, A.K. Singh. J. Neurochem. 86 (2003) 1428-1440.

103. S. Giri, M. Khan, R. Rattan, I. Singh, A.K. Singh. J. Lipid Res. 47 (2006) 1478-1492. 